\title{
Soluciones de las comunidades autónomas de régimen general a algunas deficiencias de la Ley 49/2002 de Régimen fiscal de las entidades no lucrativas en el ámbito del mecenazgo cultural
}

\author{
Esteban Palacios Ronda ${ }^{1}$
}

Recibido: 13 de enero de 2021 / Aceptado: 23 de marzo de 2021 / Publicado: 2 de junio de 2021

Resumen. La vigente Ley 49/2002 de Régimen fiscal de las entidades no lucrativas y de los incentivos fiscales al mecenazgo nació con la voluntad declarada de establecer un conjunto de estímulos aplicables a la actividad de mecenazgo en general y al cultural en particular. Sin embargo, la aplicación práctica de este principio inspirador se revela en la actualidad como una mera proposición normativa. Por su parte, las comunidades autónomas de las Islas Baleares, Comunidad Valenciana y Castila-La Mancha han promulgado sendas leyes de incentivos fiscales al mecenazgo cultural que podrían resolver en el ámbito de sus competencias algunas dificultades de que adolece la norma estatal. Con estos antecedentes analizaremos el alcance efectivo de las medidas fiscales autonómicas en sede de la imposición sobre la renta y su conexión con el régimen fiscal general del mecenazgo lo que, tras detenernos en alguna de las deficiencias advertidas, nos permitirá apuntar algunas propuestas de reforma del régimen fiscal del mecenazgo, considerado en su conjunto, que permita romper la actual estanqueidad normativa.

Palabras clave: Tercer Sector; Fiscalidad; Filantropía; Incentivos; Reforma.

Claves Econlit: B55; H30; K34; L31.

[en] Solutions from the Autonomous Communities of common regime to some deficiencies of Law 49/2002 on the tax regime of non-profit entities in the field of cultural patronage

\begin{abstract}
The current Law 49/2002 on the tax regime of non-profit entities and tax incentives for patronage was born out of the declared will to establish a set of incentives applicable to patronage activity in general and, in particular, to cultural patronage. However, the practical application to date of this commendable principle has been shown to be a mere normative proposition. The Autonomous Communities of the Balearic Islands, the Valencian Community and Castilla-La Mancha have enacted laws on tax incentives for cultural patronage that could resolve, within the scope of their competences, some difficulties encountered with state regulations. With this scenario in mind we analyze the effective scope of the regional tax measures related to income taxation and its connection with the general tax regime of patronage. After considering some of the deficiencies noted, this analysis will help propose reforms to the patronage tax regime overall that will work towards breaking the current regulatory stalemate.
\end{abstract}

Keywords: Third Sector; Taxation; Philanthropy; Incentives; Reform.

Sumario. 1. Introducción. 2. Entidades beneficiarias del mecenazgo. 3. Actos dispositivos a favor de las entidades beneficiarias del mecenazgo. 4. Régimen fiscal de los donativos y donaciones. 5. Conclusiones. 6. Referencias bibliográficas.

Cómo citar. Palacios Ronda, E. (2021) Soluciones de las comunidades autónomas de régimen general a algunas deficiencias de la Ley 49/2002 de Régimen fiscal de las entidades no lucrativas en el ámbito del mecenazgo cultural. REVESCO. Revista de Estudios Cooperativos, vol. 138, e75565. https://dx.doi.org/10.5209/reve.75565.

\section{Introducción}

La actuación de los poderes públicos en la promoción y consolidación del mecenazgo se encuentra lastrada por la complejidad y falta de coordinación de su diseminado régimen normativo. Prescindiendo de los regímenes especiales de Navarra y del País Vasco, que por su singularidad son merecedores de un estudio propio, dentro del sistema de estímulo fiscal al mecenazgo cultural hay que distinguir un marco común (delimitado por las Leyes 49/2002 y 27/2014) y, en paralelo, una normativa autonómica, desarrollada únicamente- por las comunidades autónomas de las Islas Baleares, Valencia y Castilla-La Mancha.

1 Universidad de Valencia, España.

Dirección de correo electrónico: esteban.palacios@uv.es. 
Dentro del que denominamos marco común, la Ley 49/2002, de 23 de diciembre, de régimen fiscal de las entidades sin fines lucrativos y de los incentivos fiscales al mecenazgo (en lo sucesivo, LRF-ENL) tiene una finalidad, en palabras de su Exposición de Motivos, "eminentemente incentivadora de la colaboración particular en la consecución de fines de interés general, en atención y reconocimiento a la cada vez mayor presencia del sector privado en la tarea de proteger y promover actuaciones caracterizadas por la ausencia de ánimo de lucro cuya única finalidad es de naturaleza general y pública". Ello, no obstante, las limitaciones afloradas en esta norma ${ }^{2}$ a lo largo de sus más de tres lustros de vigencia, han impedido el acomodo real de sus preceptos a la realidad de un Tercer Sector intrínsicamente variable; sin que las modificaciones introducidas en la LRF-ENL por la Ley 27/2014 (DF Quinta) puedan considerarse otra cosa que "una no reforma, en tanto no se han afrontado los problemas basilares del mecenazgo" (Blázquez, 2015: 197). En el mismo sentido, el Real Decreto-ley 17/2020, de 5 de mayo, de apoyo al sector cultural para hacer frente al impacto económico y social del COVID-19, adolece igualmente del calado suficiente para atender las necesidades que su Exposición de Motivos reconoce. Junto a esta normativa, la Ley 27/2014, de 27 de noviembre, del Impuesto sobre Sociedades (LIS) regula, en sus arts. 109 a 111, un régimen de exención parcial de aplicación a aquellas asociaciones y fundaciones no acogidas a la LRF-ENL (bien por no cumplir los requisitos en ella establecidos bien por no haber optado de forma expresa por esta posibilidad) que mantiene, con ligeras modificaciones, la configuración tradicional del régimen de exención parcial propio de las distintas leyes reguladoras de la imposición societaria pero sin que ni en su antecesora regulación ni tras la reforma operada en 2014, pueda decirse que haya tenido un especial acierto.

En el ámbito autonómico la capacidad normativa de las comunidades autónomas de régimen general para coadyuvar al impulso del Tercer Sector en general, y del mecenazgo en particular, se encuentra acotada por los límites establecidos en la Ley Orgánica 8/1980, de 22 de septiembre, de Financiación de las Comunidades Autónomas (LOFCA), complementada por las reformas introducidas por la Ley 22/2009, de 18 de diciembre, en relación a las materias que no requieren el rango de Ley Orgánica, así como en las correspondientes leyes de cesión de tributos. Al día de hoy solamente tres comunidades autónomas ${ }^{3}$ han hecho uso de la posibilidad de implantar en sus respectivos ámbitos competenciales políticas de incentivación fiscal del mecenazgo: las Islas Baleares (que ha promulgado, por una parte, la Ley 3/2015, de 23 de marzo, que regula el consumo cultural y el mecenazgo cultural, científico y de desarrollo tecnológico en adelante LMC-II.BB- y, de otra, la Ley 6/2015, de 30 de marzo, que regula el mecenazgo deportivo); la Comunidad Valenciana (Ley 20/2018, de 25 de julio, del mecenazgo cultural científico y deportivo no profesional en la Comunidad Valenciana -en adelante, LMC-CV- que deroga su predecesora Ley 9/2014, de 29 de diciembre, de impulso de la actividad cultural en la Comunitat Valenciana y, por último, la Comunidad de Castilla-La Mancha (Ley 9/2019, de 13 de diciembre, de Mecenazgo Cultural de Castilla-La Mancha -en adelante, LMC-CLaM).

Sobre la base de los materiales esbozados, plantearemos algunas de las deficiencias de las que adolece el régimen estatal de incentivos al mecenazgo y examinaremos hasta qué punto las comunidades autónomas han desarrollado, en su ámbito competencial relativo a la imposición sobre la renta ${ }^{4}$, unas políticas correctoras de las imperfecciones advertidas, contrastándose si la plasmación normativa resultante se acomoda de manera eficaz a las nuevas formas de participación de la sociedad civil en la promoción de la cultura.

\footnotetext{
Para un estudio general de la Ley 49/2002 vid. Pedreira Menéndez, J. (2003) El régimen fiscal del sector no lucrativo y del mecenazgo. Comentarios a la Ley 49/2002, de 23 de diciembre, de régimen fiscal de las entidades sin fines lucrativos y de los incentivos fiscales al mecenazgo. 1. $1^{\text {a }}$ Madrid: Civitas. 456 p.; Calvo Ortega, R. (2005) Fiscalidad de las entidades de economía social: cooperativas, mutuas, sociedades laborales, fundaciones, asociaciones de utilidad pública, centros especiales de empleo, empresas de inserción social. $1^{\mathrm{a}}$. Madrid: Civitas. 723 p.; Blázquez Lidoy, A. y Martín Dégano, I. (2012a) Manual tributario de entidades no lucrativas (asociaciones y fundaciones). $1^{\text {a }}$. Madrid: Centro de Estudios Financieros.

3 Otras comunidades autónomas han establecido determinados incentivos fiscales al mecenazgo si bien al margen de una específica ley de mecenazgo cultural. Así, v.g, el Dto. Legislativo 1/2010, de 5 de noviembre, por el que se aprueba el TR de las disposiciones legales vigentes en la Región de Murcia en materia de tributos cedidos, en su art. Dos.1 establece, entre otras, una deducción en la cuota íntegra autonómica "por las donaciones dinerarias puras y simples realizadas a favor de la Comunidad Autónoma de la Región de Murcia y entidades dependientes del sector público autonómico, las fundaciones que persigan exclusivamente fines culturales, las asociaciones culturales y deportivas que hayan sido declaradas de utilidad pública y las federaciones deportivas".

4 En el ámbito de la imposición sobre patrimonio baste recordar, por exceder el objeto de nuestro estudio, que el art. 4 de su ley reguladora (Ley 19/1991, de 6 de junio, del Impuesto sobre el Patrimonio), establece determinadas exenciones -condicionadas al cumplimiento de los requisitos en él establecidos- concernientes a: Bienes integrantes del Patrimonio Histórico; objetos de arte y antigüedades; Bienes y derechos necesarios para el desarrollo de actividades económicas o participaciones en entidades). Por su parte, el art. 9 bis Dto. Legislativo 1/2014, de 6 de junio, por el que se aprueba el TR de las disposiciones legales de la Comunidad Autónoma de las Illes Balears en materia de tributos cedidos por el Estado, establece una bonificación del $90 \%$ de la parte proporcional de la cuota que corresponda a la titularidad de pleno dominio de los bienes de consumo cultural a los cuales hace referencia el art. 5 LMC-II.BB: "la adquisición por las personas físicas o jurídicas de productos culturales como las obras de creación artística, pictóricas o escultóricas, en cualquiera de sus formatos, que sean originales y que el artista haya elaborado íntegramente y que sean únicas o seriadas. Se excluyen los objetos de artesanía y las reproducciones".
} 


\section{Entidades beneficiarias del mecenazgo}

El primer problema que debemos plantearnos consiste en la determinación de los potenciales beneficiarios de las iniciativas de mecenazgo, cuestión que, pese a su importancia y prolija regulación, dista mucho de ofrecer perfiles adecuados. En efecto, la ley estatal contiene (art. 16 y Disposiciones Adicionales) una relación cerrada de las denominadas entidades beneficiarias del mecenazgo, es decir, aquellas personas o entidades susceptibles de ser receptoras de donaciones fiscalmente incentivadas. Así, entre otras, las entidades sin fines lucrativos a las que sea de aplicación el régimen fiscal privilegiado establecido en el Título II de la Ley 49/2002, las Administraciones, las universidades públicas y otra serie de entidades. Paralelamente la norma únicamente considera, a sus efectos, como entidades sin fines de lucro a aquellas entidades enumeradas en su art. 2 (en lo que ahora interesa: fundaciones y asociaciones declaradas de utilidad pública) y siempre que cumplan los requisitos establecidos en el artículo 3 de esta Ley 49/2002.

Del mismo modo, las comunidades autónomas pueden -a sus efectos y en el ámbito de sus competenciasdelimitar las entidades beneficiarias del mecenazgo, así como relacionar qué se entiende por entidad no lucrativa. Identificadas dichas entidades beneficiarias, el alcance de los incentivos fiscales para mecenas y donantes queda acotado por las correspondientes leyes de cesión tributos de acuerdo con los criterios de distribución de la responsabilidad fiscal conformados en la LOFCA. Adviértase que esta ley reserva íntegramente al Estado la capacidad normativa concerniente al Impuesto sobre Sociedades, lo que produce el efecto de que las comunidades autónomas de régimen general, a diferencia de lo que ocurre respecto al IRPF no podrán incentivar en la imposición societaria, las donaciones a las entidades consideradas como beneficiarias del mecenazgo en su ámbito competencial (art. 19 LOFCA). Por último, la sistematización de las personas que merecen la condición de beneficiarias del mecenazgo requerirá analizar la deducibilidad fiscal de las donaciones efectuadas a entidades residentes en otros estados miembros de la Unión Europea.

\subsection{Entidades beneficiarias del mecenazgo en la Ley 49/2002}

Como decimos, el primer escollo con el que nos enfrentamos a la hora de considerar las entidades beneficiarias del mecenazgo consiste en su inadecuada regulación legal. Es cierto que el art. 16 de la Ley 49/2002, junto con las Disposiciones Adicionales $5^{\mathrm{a}}, 6^{\mathrm{a}}, 7^{\mathrm{a}}, 9^{\mathrm{a}}$ y $10^{\mathrm{a}}$ del mismo texto legal contienen una prolija enumeración de entidades potencialmente beneficiarias del mecenazgo. Sin embargo, esta mera enumeración efectuada por la LRF-ENL no permite entrever siquiera la ubicación real de sus distintos actores, por lo que problemas cotidianos del Tercer Sector han debido ser abordados por la doctrina y la jurisprudencia.

Veamos solamente un problema capital en el día a día del mecenazgo cual es el de las posibilidades de actuación de las asociaciones. Recordemos que el art. 32.1 LODA (Ley Orgánica 1/2002, de 22 de marzo, del Derecho de Asociación) previene la declaración de utilidad pública, a iniciativa de las propias entidades, de aquellas asociaciones en las que concurran determinados extremos (promoción del interés general, carácter abierto de sus actividades, retribución de sus órganos de gobierno, organización, inscripción registral y cumplimiento de sus fines), requisitos que deben concurrir de forma ininterrumpida al menos durante los dos años inmediatamente anteriores a la presentación de la solicitud.

Sin embargo, la posibilidad de que las asociaciones puedan ser consideradas como entidades sin fines lucrativos a los efectos de la LRF-ENL y beneficiarias del mecenazgo (arts. 2, 3 y 16 Ley 49/2002) plantea graves dificultades prácticas. En efecto, el acceso al régimen fiscal privilegiado tropieza con el obstáculo que significa la previa declaración de utilidad pública, la cual es conscientemente dificultada por la Administración. Veamos el porqué de esta afirmación. En primer lugar, el procedimiento establecido a tal fin por el RD 1740/2003, de 19 de diciembre, resulta excesivamente dificultoso para las asociaciones en la medida de que los requisitos legales antes enumerados deben cumplirse dos años antes desde la solicitud a la Administración. Pero, y esta segunda consideración resulta especialmente hiriente, porque existe la injustificada voluntad administrativa de privar de la condición de asociación de utilidad pública, o de rechazar la solicitud formulada en este sentido, a aquellas asociaciones que, cumpliendo los requisitos legales, ejercen cualquier tipo de actividad económica que les permite recabar fondos para atender sus actividades. Muy posteriormente en el tiempo las pretensiones de la Administración serán sistemáticamente rechazadas por el Tribunal Supremo (SSTS, de 7 octubre de 2015 y 7 de octubre de 2011) pero ello obliga a las asociaciones a agotar las distintas instancias judiciales (Palacios, 2018).

Asistimos de esta manera a lo que Jiménez (2017: 107) denomina un tratamiento desigual de "situaciones que son sustancialmente iguales (en lo que se refiere a los presupuestos para la aplicación del régimen fiscal especial y la incentivación fiscal al mecenazgo -realizar fines de interés general y carecer de ánimo de lucro-), podría ser conveniente que el legislador tributario no vinculase, en el caso de las asociaciones, entidades que conforme a su normativa sustantiva carecen de ánimo de lucro, la aplicación de la Ley 49/2002 a la declaración de utilidad pública". En definitiva, la complejidad del procedimiento para la obtención de la declaración de asociación de utilidad pública, la exigencia del transcurso de dos años para 
poder gozar de dicho reconocimiento y la inseguridad jurídica derivada del actuar administrativo rechazando o revocando arbitrariamente la declaración de utilidad pública, pueden suponer la expulsión de facto del régimen fiscal privilegiado de la Ley 49/2002 y de su calificación como entidades beneficiarias del mecenazgo, con su corolario de desincentivo fiscal para posibles donantes. De todo lo apuntado se deriva, la inaplicabilidad a las asociaciones no declaradas de utilidad pública del régimen establecido en la Ley 49/2002, con lo que se priva a estas entidades de su consideración de entidades beneficiarias del mecenazgo y, correlativamente, quedarán sujetas al régimen de exención parcial de la LIS (arts. 9.3, 109-111).

Por ello, atendiendo a la situación fáctica descrita, la doctrina aboga por la transformación de estas entidades bien en fundaciones -lo que facilitaría su acceso al régimen de la Ley 49/2002- bien directamente en sociedades mercantiles. Un sector de la doctrina defiende evitar la figura de la fundación en el entendimiento de que esta alternativa tropieza con la necesidad de contar con un patrimonio mínimo de 30.000 euros (Pedreira, 2017: 506). Por ello, en muchos casos, dice García (2017: 518) paradójicamente "les resultará más favorable simplemente convertirse en sociedad mercantil".

Entendemos sin embargo que, en primer lugar, la fórmula societaria puede desnaturalizar la idiosincrasia propia de las entidades integrantes del Tercer Sector. En segundo lugar, esta transformación no liberaría a las asociaciones de la carga fiscal indirecta propia de las personas jurídicas que, por otra parte, se pretende salvar. En tercer lugar, huelga recordar que su régimen fiscal sería menos beneficioso que el establecido en la Ley 49/2002. Por ello, cabe considerar que la opción más plausible, atendiendo siempre a las circunstancias concurrentes en cada entidad, consiste en la transformación de las asociaciones en fundaciones, sin que a ello resulte obstáculo la exigencia de una dotación fundacional mínima. A este respecto, tanto la Ley 50/2002, de 26 de diciembre, de Fundaciones como, en similares términos, las leyes de fundaciones autonómicas, únicamente exigen que la dotación sea adecuada y suficiente para el cumplimiento de los fines fundacionales; suficiencia que se presume cuando su valor económico alcance los 30.000 euros. Incluso cuando la dotación sea inferior, el fundador puede justificar su adecuación y suficiencia mediante la presentación del primer programa de actuación, junto con un estudio económico que acredite su viabilidad utilizando exclusivamente dichos recursos (Palacios, 2019).

\subsection{Entidades beneficiarias del mecenazgo cultural en las leyes autonómicas}

Frente a estas dificultades no resueltas por la ley estatal, veamos ahora si las distintas comunidades autónomas han perfilado con mayor rigor el sujeto potencialmente beneficiario del mecenazgo. En principio, estos regímenes especiales efectúan también una enumeración de las distintas entidades que pueden ser beneficiarias del mecenazgo. Así, tanto la legislación balear como la valenciana consideran como tales, y en síntesis, a las entidades sin ánimo de lucro (fundaciones y asociaciones declaradas de utilidad pública), la Administración autonómica, las Universidades (incluidas las privadas en el ámbito de la Comunidad Valenciana) así como, en términos similares a los recogidos en la ley estatal, a otras entidades dentro de sus respectivos ámbitos de actuación. Del mismo modo, la legislación castellano-manchega recoge como entidades beneficiarias del mecenazgo a la Administración Autonómica, Universidades (públicas o privadas) y a las entidades sin ánimo de lucro.

Sin embargo, la ley de mecenazgo cultural castellano-manchega, a diferencia de sus homónimas balear y valenciana o de la propia Ley 49/2002, no contiene una enumeración cerrada de las entidades que considera, a sus efectos, como entidad sin ánimo de lucro (y por tanto, entidad beneficiaria del mecenazgo), sino que se limita a definirlas como "las que así se caracterizan por la normativa reguladora de las mismas en atención a su correspondiente personificación jurídica" (art. 3.1.c LMC-CLaM). Veamos las consecuencias de este precepto.

Como se indicará al estudiar el régimen de deducciones, en esta comunidad castellano-manchega dan derecho a practicar los beneficios fiscales "las donaciones ínter vivos, puras y simples, realizadas a favor de las personas y entidades a las que se refiere el art. 3 para la realización de proyectos o actividades culturales contenidas en el art. 2" (art. 13.1 LMC-CLaM). Así pues, dos son los requisitos exigidos: (i) que las entidades destinatarias se encuentren entre las incluidas en el art. 3 y (ii) que el destino de los fondos donados sea alguna de las actividades relacionadas en el art. 2. Respecto a este último requisito, el citado precepto se produce con una amplitud suficiente como para no ser fuente de controversia alguna. Cuestión distinta es la definición de ENL contenida en el art. 3 anteriormente transcrito y que volvemos a reproducir: "las que así se caracterizan por la normativa reguladora de las mismas en atención a su correspondiente personificación jurídica". Con esta redacción, en principio, podría darse cabida a las asociaciones no declaradas de utilidad pública como entidades beneficiarias del mecenazgo pues el carácter de entidad no lucrativa es consustancial a toda asociación, con independencia de su posible declaración como asociación de utilidad pública.

Sentado lo anterior, el alcance de este art. 13 de la LMC-CLaM se concreta en el art. 11 bis.3 de la Ley 8/2013 de Medidas Tributarias de CLaM al disponer que "Los contribuyentes podrán deducirse de la cuota íntegra autonómica del impuesto, el 15\% de las cantidades donadas para fines culturales establecidos en la 
Ley Mecenazgo Cultural Castilla La Mancha, realizadas a las entidades que se establecen en el art. 3.1 de dicha ley, incluidos en el plan de mecenazgo cultural de Castila-La Mancha". Así pues, la práctica de deducciones se vincula al destino del donativo (fines culturales incluidos en el plan de mecenazgo cultural) y a la entidad destinataria (las establecidas en el art. 3.1 de la LRF-ENL). Pues bien, la regulación de dicho "Plan de Mecenazgo Cultural" se limita a establecer unas directrices generales, al tiempo que atribuye su ejecución a la "Oficina del Mecenazgo Cultural", entre cuyas funciones se encuentra la de "registrar las actuaciones, proyectos y bienes culturales de las Fundaciones, Asociaciones de utilidad pública y empresas susceptibles de recibir la colaboración privada con derecho a deducción" (arts. 7 y 8.2.c LMC-CLaM). La literalidad del precepto podría llevarnos a concluir, respecto de las asociaciones, que sólamente las declaradas de utilidad pueden ser beneficiarias del mecenazgo pues sólo ellas son susceptibles de registro. Sin embargo, ello choca frontalmente con el carácter declarativo y no constitutivo de su registro, por lo que entendemos que serían también deducibles las donaciones efectuadas, v gr., a una Congregación Religiosa (ENL -art. 3.1 LMC-CLaM-, que no posee la forma jurídica de asociación y por tanto no inscribible en la reiterada Oficina) para financiar una exposición sobre 'Arte Sacro Medieval en Toledo' (art. 2.e LMCCLaM) siempre que dicho proyecto se contemple en el plan de mecenazgo; materializándose así el principio de fomento de la cooperación "con todas las entidades, asociaciones y fundaciones culturales" reconocido por la LMC-CLaM (art. 4.e).

A este conjunto de entidades beneficiarias prescrita por las normativas autonómicas, las tres comunidades autónomas incorporan las denominadas empresas culturales: personas físicas o jurídicas, con domicilio fiscal en el territorio de la respectiva comunidad autónoma, que en nombre propio, con ánimo de lucro y de forma habitual, lleven a cabo las actividades culturales en ellas relacionadas ${ }^{5}$. Con ello se da cabida entre los sujetos beneficiarios del mecenazgo a las personas físicas o jurídicas que desarrollen actividades culturales; excluyéndose, pues, el requisito de la ausencia de ánimo de lucro para gozar de dicha consideración.

En sede de la Comunidad Valenciana, es condición necesaria la declaración de interés social de los proyectos o actividades culturales desarrollados por las entidades beneficiarias para que los mecenas puedan aplicar los incentivos fiscales previstos por donaciones, salvo que tales proyectos o actividades sean promovidos por las entidades relativos al patrimonio cultural valenciano y al fomento de la lengua valenciana (arts. 12 y 13 LMC-CV). Sin embargo, en el ámbito de la comunidad de las Illes Balears la declaración de interés social únicamente se establece como requisito, a instancia de los beneficiarios, para practicar las deducciones por donaciones realizadas a favor de las personas o entidades beneficiarias del mecenazgo cultural para la realización de proyectos o actividades culturales no contemplados en el art. 2 de la LMC-II.BB [(i) cinematografía, artes audiovisuales y artes multimedia; (ii) música y artes escénicas; (iii) artes visuales; (iv) libro y lectura (v) investigación, documentación, conservación, restauración, recuperación, difusión y promoción de su patrimonio cultural].

En definitiva, vemos como las comunidades autónomas ofrecen un más adecuado tratamiento fiscal, bien -con las matizaciones señaladas- por no exigir la declaración de utilidad pública, bien por permitir la realización de actividades económicas con ánimo de lucro. Ambas soluciones merecen una positiva valoración, en la medida de que, recordemos, el hecho de que las entidades sin fines lucrativos carezcan de ánimo de lucro en sentido subjetivo (finalidad de obtención de un beneficio partible) "no excluye la posibilidad de que persigan sus fines o su objeto social, incluso de interés general, mediante la realización de actividades económicas y de que éstas generen beneficios sujetos a gravamen en el IS, impuesto este en el que su carácter no lucrativo se tiene en cuenta con diverso alcance según los casos" (Montesinos y Palacios, 2020: 141).

\subsection{Entidades residentes en otros estados de la UE como beneficiarias del mecenazgo}

Un problema adicional derivado de la imprecisa conceptuación del beneficiario en la Ley 49/2002 es el que se plantea ante la posible colaboración del mecenas con entidades residentes en otros estados de la Unión Europea $^{6}$. Como pone de manifiesto Martínez Bárbara (2019: 12), la realidad económica y social evoluciona "a un ritmo más rápido que la legislación que la rige, que sigue manteniendo ciertas barreras legales que imposibilitan el libre funcionamiento del libre mercado y sus libertades fundamentales". En principio, la Ley 49/2002 considera entidades beneficiarias del mecenazgo, entre otras, a las fundaciones y delegaciones de fundaciones extranjeras (no así a las asociaciones) inscritas en el Registro de Fundaciones (arts. 16 y 2.a y d). Sin embargo, el principio de no discriminación propio de los Tratados de la Unión Europea (Maastrich 0702-1992; Lisboa 13-12-2007) "obliga a que una exención o un beneficio fiscal que rija en un estado miembro se aplique a todos los contribuyentes en dicho Estado sin que puedan establecerse distinciones por

Artículos. 4.1.e) LMC-II.BB; $3.1 \mathrm{~g}$ ) y h) de la LMC-CV y 3 LMC-CLaM.

A este respecto vid. el trabajo de López Ribas, S. (2014) "Incentivos fiscales sin fronteras para fundaciones y donantes europeos". Crónica Tributaria, No153, pp. 221-259. 
el lugar donde resida la persona o entidad contribuyente o por el Estado miembro en que inviertan o del que provengan sus capitales" (STSJ de Cataluña 722/2017, de 9 de octubre).

Frente al silencio de la Ley 49/2002, la DGT entiende (Consulta V4637/2016, de 2 de noviembre), que el hecho de que una organización benéfica sea residente fiscal en otro estado miembro, no debe suponer un obstáculo a estos efectos, tal y como había reconocido el Tribunal de Justicia de la Comunidad Europea, entre otras, en su Sentencia de 27 de enero de 2009 (Asunto C-318/07) al declarar que: "el artículo 56 CE se opone a una normativa de un Estado miembro en virtud de la cual, en lo que se refiere a las donaciones efectuadas en favor de organismos de utilidad pública reconocida, sólo se concede la deducción fiscal en relación con las donaciones efectuadas en favor de organismos establecidos en el territorio nacional, sin posibilidad alguna de que el contribuyente demuestre que las donaciones entregadas a un organismo establecido en otro Estado miembro cumplen los requisitos establecidos en dicha normativa para la concesión de tal beneficio".

Lógicamente, la deducibilidad fiscal de la donación en el Estado de residencia del donante supone una merma de ingresos fiscales en dicha jurisdicción y, como contrapartida, la aplicación de recursos a actividades de interés general en otro Estado. Ante esta situación, afirma Pedreira (2017: 501), "si las actividades de interés general se desarrollan en un tercer país, salvo cuando estamos en presencia de acciones de cooperación al desarrollo, considero que el donativo no debería ser deducible en España". Continúa este autor indicando que "si tales actuaciones no se desarrollan en España, sino en un tercer Estado, se estará perjudicando fiscalmente al país de residencia del donante, frente al receptor de la donación, de ahí que sea preciso que el sistema se introduzca con carácter general en toda Europa".

Pese a su trascendencia, este imperativo (derivado de la obligación de eliminar obstáculos a la libre circulación de capitales en el espacio comunitario) y preterido por la legislación estatal, únicamente ha sido atendido por la Comunidad Valenciana, la cual (art. 3.1 y 2 LMC-CV) extiende la calificación de beneficiarias del mecenazgo a "las personas o entidades objetivamente comparables a las en ella previstas con sede en otras comunidades autónomas, estados miembros de la Unión Europea o estados asociados del espacio económico europeo que desarrollen proyectos o actividades declarados de interés social en los términos de la ley valenciana", acomodando la normativa autonómica a las disposiciones del derecho comunitario (art. 56 del Tratado Constitutivo de la CE y art. 40 del Acuerdo sobre Espacio Económico Europeo, de 2 de mayo de 1992, de acuerdo con los fundamentos de la STJUE de 11-01-2011).

\subsection{Obligaciones de información}

Otro ámbito en el que la legislación de las comunidades autónomas apunta el camino a seguir por la normativa estatal concierne a la necesaria racionalización del cumplimiento de las obligaciones formales impuestas por la LRF-ENL a las entidades beneficiarias del mecenazgo. En efecto, estos obligados tributarios deben (so pena de sanción del art. 198 LGT) expedir una certificación justificativa de la efectividad de los donativos, donaciones y aportaciones deducibles en la imposición de los donantes (art. 24 Ley 49/2002) y remitir a la Administración tributaria una declaración informativa (Modelo 182) relativa a las certificaciones que hayan expedido como justificación de los donativos, donaciones y aportaciones deducibles, en la que conste determinada información, entre otra: identificación y NIF de donantes y aportantes; importe del donativo o aportación y, si estos fueran en especie, su valoración e indicación de si el donativo o aportación da derecho a la aplicación de alguna de las deducciones autonómicas.

El problema se reproduce en similares términos en las legislaciones autonómicas. Así la ley balear se refiere a la emisión de un "certificado expedido por el órgano competente de la entidad donataria o una declaración jurada de la persona física donataria" (art. 9 LMC-II.BB). La Comunidad Valenciana exige la expedición de certificación "por la persona o entidad donataria" (art. 4 Ley 13/1997 Cesión Tributos Comunidad Valenciana). La ley castellano-manchega previene que la efectividad de las donaciones, contrato de comodato o convenios de colaboración se justificará mediante certificación expedida por la persona o entidad beneficiaria (arts. 14, 16 y 18 LMC-CLaM).

Entre las comunidades autónomas solamente la castellano-manchega parece reparar en la necesidad de suavizar esta obligación, estableciendo algunas iniciativas tal vez embrionarias pero que no dejan de estar orientadas en la dirección adecuada. Así, la DA Primera de la LMC-CLaM prevé el desarrollo de una aplicación informática que facilite la gestión del Mecenazgo Cultural, creando un enlace en la sede electrónica de la Junta de Comunidades de Castilla-La Mancha, que posibilite realizar de forma electrónica donaciones a las personas o entidades que desarrollen actividades y proyectos incluidos en el art. 2 de su ley reguladora, incluidas en el Plan de Mecenazgo Cultural o declaradas actividades prioritarias de mecenazgo para la Región en su Ley de Presupuestos. En definitiva, y junto a la generalización de la citada sede electrónica por las distintas administraciones, la solución estriba en, por una parte, ampliar el plazo de presentación del citado modelo 182 "cuando el número de donantes fuera significativo" y, de otra, excluir de esta obligación de información "a las donaciones que no llegaran a un determinado umbral" atendiendo a los principios de proporcionalidad y limitación de costes indirectos (Blázquez y Martín, 2012b: 33). 


\section{Actos dispositivos a favor de las entidades beneficiarias del mecenazgo}

Una vez identificadas las personas o entidades potencialmente beneficiarias del mecenazgo, examinemos ahora una segunda deficiencia de la Ley 49/2002 cual es la insuficiente concreción de los actos dispositivos de donantes y mecenas susceptibles de ser incentivados fiscalmente en la imposición personal o, dicho de otro modo, cuáles son los actos a cuya realización el legislador anuda algún tipo de beneficio fiscal.

En principio, la Ley 49/2002 se refiere al derecho a practicar las deducciones en ella establecidas por los "donativos, donaciones y aportaciones irrevocables, puros y simples" (art. 17) realizados en favor de las entidades beneficiarias del mecenazgo, regulando también lo que la ley denomina "otras formas de mecenazgo", a saber: los convenios de colaboración empresarial en actividades de interés general (art. 25), los gastos realizados para los fines de interés general del art. 3.1 de la ley (art. 26) y los porcentajes de deducción incrementados relativos a programas de apoyo a acontecimientos de excepcional interés público (art. 27).

Sentado lo anterior, detengámonos ahora en determinados extremos que debieran ser tenidos en cuenta por el legislador en una futura reforma integral del mecenazgo y la forma en que, en mayor o menor medida, han sido abordados por las normativas objeto de estudio; en particular: el carácter irrevocable, puro y simple de los donativos, las aportaciones efectuadas a título de comodato, la prestación de servicios gratuitos y el micromecenazgo.

\subsection{El carácter irrevocable, puro y simple de los donativos y donaciones}

El art. 17 de la Ley 49/2002 exige que las donaciones sean necesariamente "irrevocables, puras y simples" para poder ser fiscalmente incentivadas. Sin embargo, con la indicación genérica efectuada por la LRF-ENL al carácter de "irrevocables, puros y simples" de las donaciones no se da razón suficiente de la variada naturaleza de los actos de liberalidad que pueden ser realizados en favor de las ENL, restringiéndose en consecuencia el alcance de los actos dispositivos susceptibles de gozar de los incentivos fiscales al mecenazgo en los términos que desarrollaremos en el siguiente apartado. A juicio de Casanellas (2016: 51) siguiendo a Jiménez Díaz (1998: 198)- esta exigencia se traduce en "la imposibilidad de que tales aportaciones vayan acompañadas de cláusulas de reversión, limitaciones temporales o determinaciones accesorias dependientes de la exclusiva voluntad del donante más allá de los requisitos que la Ley impone y a los que el donante se adhiere como condición del disfrute de los beneficios fiscales que la propia ley ofrece". Por ello, la DGT rechaza la concurrencia de cualquier contrapartida del donatario para con el mecenas junto al acto dispositivo, so pena de pérdida de la deducibilidad fiscal de la donación efectuada.

A este respecto la DGT, en la Consulta V1503/2014, de 9 de junio, se pronuncia acerca del derecho a practicar las deducciones previstas en la LRF-ENL por las cantidades aportadas a una asociación declarada de utilidad pública, que desarrolla sus actividades en el ámbito de las Humanidades y Ciencia, Artes Escénicas y Plásticas, Cine.... Se planteó por la consultante la posibilidad de incorporar la figura del "amigo colaborador" y "amigo benefactor" los cuales, a cambio de satisfacer una aportación anual, obtienen determinados derechos, v.gr.: el acceso a las salas de exposiciones de la asociación, descuentos en la librería, inserción del nombre del donante en los agradecimientos de la página web de la entidad, regalo de una selección de publicaciones, invitación exclusiva a espectáculos, etc. La DGT negó el carácter de donación de dichas aportaciones al considerar que no son sino la contraprestación por el derecho a percibir distintas prestaciones "puesto que el ánimo de liberalidad se ve desvirtuado por el hecho de recibir determinadas prestaciones, sin que a dichos efectos sea relevante que el valor de las mismas entienda la consultante que es inferior al de las aportaciones realizadas".

Entendemos, por el contrario, que la delimitación de los actos de disposición fiscalmente incentivables debe ser interpretada atendiendo a la finalidad de la norma, es decir, considerando la específica naturaleza del acto dispositivo a incentivar: la colaboración particular en la consecución de fines de interés general. Por ello, atendiendo a los principios en que se fundamenta la vigente LRF-ENL, y que debieran inspirar su pospuesta reforma, la norma ha de velar por el efectivo cumplimiento del mecenazgo haciendo abstracción del fundamento volitivo del donante, admitiendo que, junto al enriquecimiento del donatario, puede concurrir en este acto de liberalidad algún reconocimiento público para con el donante o incluso una proporcionada contraprestación en favor del mecenas siempre que con ello no se desnaturalicen los fines de la entidad beneficiaria.

Frente a la rigidez de la normativa estatal, las comunidades de Valencia y la castellano-manchega enfocan más adecuadamente el problema permitiendo una cierta compensación del donante que no puede ser considerada contraprestación pero estimula su reconocimiento social, lo cual indudablemente redunda en beneficio de las actuaciones de mecenazgo. Así el art. 5 de la LMC-CV obliga a la conselleria competente en materia de cultura a realizar actuaciones encaminadas a la publicidad de proyectos y actuaciones declaradas o consideradas de interés social para la captación de posibles mecenas, la promoción del reconocimiento social de las personas y entidades mecenas, el fomento de la participación de los sectores sociales interesados 
en el mecenazgo y en el impulso de la actividad cultural, o la promoción del reconocimiento social de aquellas personas físicas o jurídicas que realizan acciones relevantes de mecenazgo cultural.

En el mismo sentido, el art. 9 de la LMC-CLaM -relativo al "reconocimiento a la colaboración privada en la cultura"- señala que la Oficina del Mecenazgo Cultural dará visibilidad pública, en su sede electrónica, a las personas que hayan realizado actuaciones de mecenazgo. Igualmente, se crean los premios a la colaboración privada en la cultura de Castilla-La Mancha, en sus modalidades para personas físicas y para personas jurídicas, que tienen por objeto reconocer la colaboración en la financiación de la cultura.

Salta inmediatamente a la vista que las actuaciones de ambas comunidades autónomas orientan en la dirección adecuada la necesaria reforma del régimen fiscal del mecenazgo. Estas iniciativas, insuficientes pero correctamente encaminadas, responden, a nuestro juicio, a un planteamiento mucho más realista, especialmente en el ámbito empresarial, en la medida de que las políticas de responsabilidad social corporativa conllevan una necesaria visibilización de su actuar filantrópico que, necesariamente, produce un retorno indirecto de sus acciones de mecenazgo en términos de reputación corporativa y define en sus justos términos el carácter "puro y simple" de las donaciones.

\subsection{Comodato}

Consideremos a continuación una debilidad de la Ley 49/2002, derivada del silencio que guarda ante una operación, relativamente frecuente en la práctica, cual es aquella en cuya virtud una persona cede a una ENL el uso temporal y gratuito de un bien determinado; o en la decimonónica terminología del Código Civil, el comodato, definido por el art. 1741 del citado texto legal al establecer que "el comodante conserva la propiedad de la cosa prestada. El comodatario adquiere el uso de ella, pero no los frutos, si interviene algún emolumento que haya de pagar el que adquiere el uso, la convención deja de ser comodato".

La Ley 49/2002 no recoge expresamente la aplicación a estos contratos del régimen fiscal de las donaciones y aportaciones establecido en dicha norma. No obstante, la DGT (Consultas V2549/2010 de 26 de noviembre y V1524/2011 de 13 de junio) considera que la cesión gratuita que caracteriza el contrato de comodato encajaría dentro del concepto de donativos de derechos a que se refiere el art. 17.1.a) de la Ley 49/2002 permitiendo, en consecuencia, practicar las deducciones previstas en su Título III. Paralelamente, las reseñadas consultas establecen que la base de esta donación de derechos vendrá dada por el valor contable que tuviesen en el momento de la transmisión y, en su defecto, el determinado conforme a las normas del Impuesto sobre el Patrimonio, es decir, su precio de mercado (arts. 18.1.b) LRF-ENL y 24 Ley 19/1991, de 6 de junio, del Impuesto sobre el Patrimonio). Sin embargo, frente a esta conceptualización, entendemos con Martín Dégano (2017a: 640), que el comodato sólo debiera ser considerado donación en "aquellos supuestos en los que el comodante sufre un empobrecimiento efectivo por dejar de percibir algo o por no poder utilizar el bien no fungible en su actividad económica". Por ello procede cuestionar "si deben tener derecho a beneficios fiscales operaciones donde el comodante no tenga, realmente, un empobrecimiento. Pensemos en el caso de cesión de cuadros a un museo (...). En estos casos, un uso inadecuado de esta figura podría dar lugar a un aprovechamiento ilícito por parte de ciertos comodantes" (Blázquez y Martín, 2012: 18).

Pese a lo acertado que resultan estas consideraciones, la DGT (Consulta V0613/2020, de 31 de marzo) entiende, sin mayor motivación, que a efectos del IRPF es deducible, como donación de derechos, la entrega en comodato de obras de arte, no afectas a ninguna actividad económica que pudiera desarrollar el comodante, a instituciones religiosas o museos a los que sea de aplicación el régimen fiscal establecido en el Título II de la Ley 49/2002. Resuelve la DGT, manteniendo el criterio manifestado en las consultas antes reseñadas, que la operación encajaría dentro de los donativos de derechos a que se refiere el art. 17.1.a) de la Ley 49/2002, siendo aplicables los arts. 17, 18 y 19 de dicha LRF-ENL. Ello supone en definitiva considerar exentas en sede del IRPF del comodante la renta del donante o aportante las ganancias patrimoniales y las rentas positivas que se pongan de manifiesto con motivo de la operación, remitiendo en cuanto a su valoración, sin entrar en otras consideraciones, al valor de mercado del derecho en el momento del devengo de acuerdo con el art. 24 de la Ley 19/1991. Insistimos en que la DGT no fundamenta por qué considera admisible la deducción, pero lo cierto es que el principio de legalidad obliga a que las deducciones fiscales sean recogidas expresamente por la ley. De lo contrario el contribuyente queda al albur de la voluntad administrativa, comprometiendo la seguridad jurídica de sus futuras decisiones.

Un segundo problema derivado de la consideración del comodato como operación susceptible de integrar la base de deducción concierne a la necesidad de concretar su valoración, cuestión obviamente compleja en la medida de que debe atender a la casuística que puede presentarse tanto respecto al comodante (persona física o jurídica) como en relación al bien cedido (bienes muebles o inmuebles, afectos o no a una actividad económica, y susceptibles, en su caso, de generar rendimientos o imputaciones de rentas inmobiliarias -art. 18 Ley 49/2002, art. 24 LIP y arts. 6.5, 85, 28.4 LIRPF-). Así, en el caso de bienes afectos a explotaciones económicas la Ley 49/2002 se refiere a su valor contable en el momento de la transmisión (art. 18). Sin embargo, señala Martín (2017a: 643) "esta regla no está pensada para un comodato que implica la cesión temporal de una cosa sino para un contrato traslativo de la propiedad como es la donación irrevocable. De 
hecho, en la propia Ley 49/2002 se ha previsto una norma especial de valoración para cuando se dona un derecho temporal como es el usufructo (art. 23). Pensamos que sería más lógico determinar la valoración del comodato atendiendo a la amortización del bien o la rentabilidad que produce durante el tiempo de contrato".

Sentado lo anterior, partiendo a efectos de su valoración de la remisión normativa al valor contable, habrá que atender al plazo contractual de la cesión. Así, si ésta alcanza o se aproxima a toda la vida económica del bien cedido, el cedente deberá dar de baja el importe contable del bien, ya que no se espera que en el futuro pueda recuperar este importe. En otro caso, si el plazo de la cesión difiere significativamente de la vida económica del bien cedido, el cedente determinará el valor del importe no recuperable del valor del bien durante el plazo de cesión, registrando la pérdida originada (cuantificable en el valor de la amortización que hubiera correspondido registrar durante el periodo de cesión) en el ejercicio de cesión.

Tratándose de elementos no afectos a una actividad la dificultad no es menor. Así, en el caso de inmuebles podemos entender como valor de mercado la renta dejada de percibir en el caso de que el inmueble estuviere arrendado. En el caso de bienes muebles para su valoración habría que acudir, en su caso, a peritación cualificada. Esta disfunción normativa podría evitarse, a juicio de Casanellas (2016: 56), recurriendo a criterios objetivos valorando el comodato "de acuerdo con las normas establecidas para la donación temporal de derechos, como el usufructo, supuestos que sí están expresamente establecidos en la norma estatal de mecenazgo".

Veamos a continuación cómo enfocan las comunidades autónomas los problemas apuntados, adelantando la conclusión de que en el ámbito autonómico las comunidades ahora consideradas marcan -si bien parcialmente- la senda que debería tomar la legislación estatal. Así, las tres normativas ${ }^{7}$ examinadas establecen, en similares términos, la figura del comodato como mecanismo específico de incentivo fiscal al mecenazgo cultural. Dicho incentivo acompaña al derivado de las donaciones y legados así como, excepto en el caso de la Comunidad Valenciana, el derivado de los convenios de colaboración empresarial, pero limitan los bienes que pueden ser objeto de cesión de uso fiscalmente incentivada: bienes de interés cultural, obras de arte y locales para la realización de actividades culturales.

Por lo que a la base de deducción se refiere, las tres normativas cuantifican la cesión de uso (con independencia de la afectación o no del bien a una actividad económica) por el importe anual que resulte de aplicar, en cada uno de los periodos impositivos de duración del contrato de comodato, el $4 \%$ a la valoración del bien efectuada por el organismo competente. Tratándose de locales para la realización de proyectos o actividades culturales, la valoración de la base de deducción se cuantifica aplicando el $4 \%$ sobre el valor catastral. En definitiva, tanto en lo referente a la plasmación legislativa del comodato como acto generador del derecho a practicar deducciones como en la valoración de la figura, las comunidades autónomas marcan el camino a la legislación estatal garantizando la seguridad jurídica del contribuyente. No obstante, la remisión efectuada, en el caso de locales, a un criterio objetivo cuál es su valor catastral, si bien dota de seguridad a la operación, la aleja de lo que, a nuestro juicio, debiera ser una adecuada valoración, es decir, el valor de mercado del bien o derecho cedido en uso.

Así pues, la cesión de uso de un determinado bien o derecho puede generar el derecho a practicar (de acuerdo con el art. 17 de la Ley 49/2002 y atendiendo al criterio evacuado por la DGT en sus consultas) una deducción en la cuota íntegra, tanto estatal como autonómica, del IRPF. Para la valoración de la base de deducción derivada de dicha cesión habrá que estar a si se trata o no de un bien afecto a una actividad económica. Al tiempo, a resultas de ese mismo acto de cesión y de ese mismo bien o derecho procederá, en su caso, la aplicación de las deducciones establecidas por cada comunidad autónoma. Dichas deducciones minorarán exclusivamente la cuota íntegra autonómica del IRPF. Sin embargo, la valoración de esta última base deducción (la autonómica) diferirá de la valoración efectuada de acuerdo con la Ley 49/2002 a resultas de los distintos criterios valorativos contenidos en los respectivos cuerpos normativos, es decir, en la LRFENL y en las leyes de mecenazgo cultural analizadas.

Consideremos, por ejemplo, un contrato de comodato recayente sobre un elemento de transporte, no afecto a una actividad económica, propiedad de una persona física y cuyo uso es cedido a una entidad acogida a la Ley 49/2002. A resultas de dicha cesión el comodante practicará, en tanto donación de derechos, la correspondiente deducción IRPF (cuotas íntegras estatal y autonómica) al amparo de la LRF-ENL. Sin embargo, entendemos que esta cesión no le permitirá practicar la deducción autonómica por cesión de uso dado que el bien cedido no se encuentra entre los relacionados en dicha norma como generador del derecho a practicar tal deducción autonómica sin que, en principio, quepa reconducir este acto dispositivo a las donaciones de bienes y derechos, igualmente recogidos en dicha normativa, debiendo primar restrictivamente su no inclusión entre los bienes expresamente relacionados como generadores del derecho a practicar esta deducción autonómica por el concepto de comodato. 


\subsection{Prestaciones de servicios}

Un problema añadido en sede de mecenazgo consiste en la calificación de las prestaciones gratuitas de servicios a las ENL. Como venimos indicando, la Ley 49/2002 limita los actos dispositivos susceptibles de integrar la base de deducción a los "donativos y donaciones dinerarios, de bienes o de derechos" omitiendo entre dichos actos, en lo que ahora interesa, a las donaciones de servicios prestados por personas físicas o jurídicas (art. 17 LRF-ENL). Este precepto patentiza la desconexión existente entre el legislador y la realidad social en la medida en que olvida conductas tan habituales en la realidad del mecenazgo como son las prestaciones de servicios gratuitos efectuados tanto por personas físicas (en el ejercicio de una actividad económica o al margen de ella) como por personas jurídicas. De esta manera se produce la paradoja de que determinados donantes, además de carecer de incentivo fiscal, se verán penalizados por su colaboración altruista, en tanto que resultarán obligados a integrar en sus respectivas bases imponibles unos beneficios irrealmente estimados. Distingamos según se trate de personas físicas empresarios, de personas físicas no empresarios o de sociedades.

Tratándose de personas físicas empresarios el art. 28.4 LIRPF establece una imperativa norma específica de valoración (por el valor de mercado): para calcular el rendimiento neto de las actividades económicas a integrar por un empresario en la base imponible del IRPF se atenderá al valor normal de mercado, tanto si son bienes o servicios objeto de la actividad del contribuyente que éste preste o ceda a terceros gratuitamente o los destine al uso o consumo propio como si media contraprestación notoriamente inferior al valor normal de mercado.

Esta disonancia de la norma se manifiesta igualmente si consideramos la prestación de servicios altruista efectuada por personas físicas no empresarios (Ley 45/2015, de 14 de octubre, de Voluntariado). En estos supuestos, la presunción del carácter retribuido de las prestaciones de servicios susceptibles de generar rendimientos del trabajo contenida en el art. 6.5 LIRPF $^{8}$ decae atendiendo a la naturaleza de la entidad destinataria. Cuestión distinta es el resarcimiento de los gastos en que incurre el personal voluntario. A este respecto, traigamos a colación la Consulta V2214/2020, de 30 de junio. La consultante es una asociación que gestiona dos orquestas integradas por niños que tocan para otros niños "con el fin de atraerlos a la música". La entidad tiene firmado un acuerdo de voluntariado con músicos y directores, mediante el cual estos colaboran con la asociación y tienen solamente derecho a ser compensados de los gastos de transporte y comida en que incurran. Entiende la DGT (reiterando el criterio mantenido en su CV2569/2015, de 4 de septiembre, relativa a la indemnización para gastos de manutención y transporte percibida por voluntarios de protección civil por los servicios de vigilancia que prestan en las playas) que la compensación económica a percibir por los voluntarios responde al concepto de rendimientos del trabajo establecida en el art. 17.1 LIRPF, sin que les sea de aplicación el régimen de dietas exentas previsto en el art. 9 de su Reglamento el cual solo es de aplicación "a los contribuyentes que perciben rendimientos del trabajo como consecuencia de una relación laboral (estatutaria en el caso de los funcionarios públicos) en la que se dan las notas de dependencia y alteridad".

No obstante, señala la DGT, cabe la posibilidad de que pueda apreciarse la existencia de un "gasto por cuenta de un tercero" por lo que distingue: "si la asociación pone a disposición de los músicos y directores el medio de transporte y, en su caso, el alojamiento, no existirá renta para los mismos, pues no se produce ningún beneficio particular para ellos"; por el contrario, "si la asociación reembolsa a los músicos y directores los gastos en los que han incurrido por desplazarse hasta el lugar donde van a prestar sus servicios y estos no acreditan que estrictamente vienen a compensar los gastos en que incurren, o les abona una cantidad para que decidan libremente cómo asignarla, estaríamos en presencia de una renta dineraria sometida al Impuesto que procedería calificar como rendimientos del trabajo". En este último supuesto pudiera parecer que la DGT suaviza su interpretación respecto al mantenido en su precedente Consulta V2569/2015, al introducir la figura del "gasto por cuenta de un tercero" condicionada a la estricta justificación de cada gasto y rechazando una compensación de gastos a tanto alzado. Sin embargo, en este planteamiento continúa subyaciendo la querencia administrativa a conceptuar estas percepciones como rendimientos del trabajo no exentos. Así, por ejemplo, resultará de difícil justificación los gastos de desplazamiento en que pueda incurrir el voluntariado si utiliza para sus desplazamientos medios de transporte propios (descartada la amortización del vehículo o la imputación de la parte proporcional de la prima de seguro).

A nuestro juicio, este criterio administrativo se mantiene: se califica el resarcimiento de gastos como rendimientos del trabajo. Antes al contrario, como señala Carbajo (2017: 445), "lo que recibe el voluntario es una compensación de gastos que éste, previa o simultáneamente a la realización de su actividad, ha tenido que ejecutar en beneficio de la misma: transporte, seguro, comida, etc. y tales gastos de consumo se devuelven por la entidad no lucrativa con la que se relaciona, no siendo renta para su perceptor

\footnotetext{
Artículo 6.5 LIRPF "Se presumirán retribuidas, salvo prueba en contrario, las prestaciones de bienes, derechos o servicios susceptibles de generar rendimientos del trabajo o del capital".
} 
(voluntario) y sí gasto deducible para la entidad que paga tales gastos". Paralelamente, junto a esta calificación de las cantidades percibidas por el voluntariado como rendimientos del trabajo, se rechaza la deducibilidad de estas prestaciones de servicios gratuitas lo que, como señala Jiménez (2017: 110), provoca "dos tipos de discriminaciones: a) favorece al factor capital frente al factor trabajo, lo que resulta paradójico en el espacio social del Tercer Sector o de la Economía Social, b) discrimina entre empresarios y trabajadores, dado que en la base de la deducción de los bienes fabricados y donados por los empresarios se tiene en cuenta el coste del trabajo que se imputa a los bienes, sin embargo el coste del servicio no es deducible en el caso del trabajo de los voluntarios".

Y ya, en el ámbito de la imposición societaria, las sociedades, con base en la Responsabilidad Social Corporativa, pueden prestar servicios gratuitos a las entidades no lucrativas poniendo a disposición de estas entidades sus medios materiales y humanos. Ahora bien, la prestación de estos servicios, en tanto liberalidad, impedirá la deducibilidad fiscal en sede del IS de los gastos asociados a los servicios así prestados (art. 15.e LIS). Ello no obstante, cabe plantearse si estas prestaciones de servicios se corresponden con el concepto de liberalidad pues "jurídicamente es dudoso que los administradores de una sociedad de capital puedan hacer actividades no dirigidas, directa o indirectamente, a maximizar el valor de la empresa. Y, económicamente, porque las actividades de filantropía se vinculan a lograr a largo plazo mayores beneficios o mayor valor de la empresa" (Blázquez, 2017: 274).

En cualquier caso, junto a la no deducibilidad fiscal de estos gastos, nos encontramos con que estas prestaciones, dado que no constituyen una "donación de bienes o derechos", quedan expulsadas del régimen de deducciones establecido en el art. 17 de la Ley 49/2002. A este respecto, traigamos a colación la Consulta V1403/2007, de 28 de junio de 2007, formulada por una fundación que gestionaba un banco de alimentos. Esta fundación precisaba de la colaboración de empresas de transporte para llevar los alimentos donados hasta sus almacenes. Se planteó si el coste del servicio de transporte, que las empresas de transportistas realizan gratuitamente podía ser considerado a efectos de la desgravación fiscal propia de la Ley 49/2002. La DGT rechazó esta posibilidad, a nuestro juicio equivocadamente, entendiendo que la prestación de un servicio de transporte de forma gratuita no se incluye entre las enumeradas en el art. 17 de la LRF-ENL, en la medida que se trata de una prestación de servicios y no una donación de bienes o derechos, por lo que no dará derecho a practicar deducción alguna.

Visto lo anterior, planteémonos ahora hasta qué punto las leyes autonómicas califican adecuadamente estas operaciones. En principio las distintas comunidades autónomas no abordan tampoco de forma expresa la deducibilidad de las prestaciones de servicios. Ahora bien, la ley balear establece que la práctica de las deducciones y las reducciones exige la acreditación de la efectividad de la donación, mediante un certificado expedido por el órgano competente de la entidad donataria o una declaración jurada de la persona física donataria. Dicha certificación o declaración deberá contener el "importe de la valoración de la donación en el supuesto de donaciones no dinerarias o de prestación de servicios a título gratuito", por ello cabe entender implícitamente incluidas las prestaciones de servicios como actos susceptibles de integrar la base de la deducción si bien esta ley autonómica guarda silencio en cuanto a su valoración (art. 9.2.d LMC-II.BB).

\subsection{Micromecenazgo}

La Ley 5/2015, de 27 de abril, "de fomento de la financiación empresarial" regula, entre otros extremos, el denominado micromecenazgo o crowdfunding, es decir, la "financiación en masa canalizada a través de Internet con la finalidad de recaudar fondos para un determinado proyecto" (Rodríguez de las Heras, 2013: 101). Dicha ley limita su alcance exclusivamente a las modalidades de financiación ${ }^{9}$ colectiva en las que prima su componente financiero -vía intereses o participación en beneficios-, es decir, a las basadas en aportaciones de capital (Rending o debt-based) y a las basadas en préstamos (Equity-based crowdfunding), por lo que resultan excluidas de su ámbito aplicación las modalidades de financiación colectiva basadas en donaciones con un ánimo de entera liberalidad (Donation-based crowdfunding) y el Reward-based crowdfunding o financiación colectiva a cambio de una recompensa. Es decir, deja fuera de su ámbito de aplicación la captación de recursos estrictamente altruista para allegar recursos a ENL así como aquéllas en las que existe una recompensa simbólica.

Si buscamos el encaje del micromecenazgo en la LRF-ENL, y dado que la Ley 49/2002 no ha sido objeto de adecuación alguna que contemple esta forma financiación -de suerte tal que "la incidencia fiscal de las distintas estructuras de este tipo de financiación colectiva se encuentra deslavazada a lo largo de los principales impuestos que conforman nuestro sistema fiscal" (Suberbiola, 2017: 388)- aflorarán de inmediato las debilidades normativas reproduciéndose en esta nueva realidad social los problemas ya evidenciados.

(i) En efecto, no es inhabitual la existencia de recompensas simbólicas que acompañan al mecenazgo cultural (v.gr. pequeños descuentos en el merchandising o en la venta de entradas). Sin embargo,

9 In extenso véase Sanz Gómez, R.J. y Lucas Durán, M. (2015) "Implicaciones tributarias del crowdfunding o financiación colectiva” Quincena Fiscal. No9, pp. 19-69. 
como ya hemos expuesto, tratándose de donaciones, donativos y aportaciones, los beneficios al mecenazgo quedan condicionados al carácter irrevocable, puro y simple de dichos actos dispositivos quedando proscrita cualquier tipo de contraprestación. En estos supuestos habrá que estar a la significatividad de la recompensa respecto al valor de lo donado. Es decir, "cuando la recompensa no tenga valor económico, o tenga un valor simbólico o poco significativo respecto de la prestación principal, debería aplicarse la deducción; en otras palabras, cuando exista una clara desproporción entre el valor de lo donado y la contraprestación recibida ... si las recompensas de muy escaso valor económico y carácter accesorio no desvirtúan la naturaleza auténtica de la donación de la aportación, podría establecerse un límite cuantitativo al valor del retorno recibido por debajo del cual se aplicasen, en todo caso, las reglas aplicables a la donación" (Moreno, 2017: 332 y 339).

Paralelamente, a efectos de la Ley 49/2002 no cabe desmembrar la naturaleza de los actos dispositivos. Si concurre contraprestación para el donante ya no cabe hablar de donaciones puras y, en consecuencia, queda vetado al acceso al régimen de deducciones establecido en la LRF-ENL. Por el contrario, la posibilidad de desdoblar la operación, vetada en sede de la Ley 49/2002, sí que es contemplada por el legislador fiscal en el ámbito del crowdfunding. Así, la DGT (Consulta V0055/2020, de 14 de enero) califica como híbrida una operación de financiación de la edición de un libro sin ánimo de lucro mediante aportaciones realizadas por personas anónimas a través de la fórmula crowdfunding en la modalidad de recompensa. Las empresas financiadoras percibían a cambio de su aportación un ejemplar del mencionado libro, cuyo coste se sobreentiende inferior al de la financiación recibida de cada aportante. Considera la DGT que "teniendo en cuenta la falta de equivalencia entre las prestaciones de los financiadores y la del consultante, el negocio jurídico descrito en la consulta puede calificarse como donación especial de las reguladas en el art. 619 del Código Civil .... habrá que distinguir por un lado el importe de la aportación que, en su caso, exceda del valor atribuible a los bienes y derechos a entregar a los aportantes, los libros, que estará sujeto al ISD, siendo sujeto pasivo el consultante que recibe la donación; y la parte en que coinciden el valor de lo aportado y el valor de mercado de los bienes y derechos a recibir por los aportantes, constituyendo dicha parte un ingreso de la actividad económica a efectos del IRPF'.

(ii) En segundo lugar en sede del micromecenazgo se manifiestan igualmente las limitaciones derivadas del cumplimiento de los requisitos para poder acogerse al régimen fiscal de la LRF-ENL (art. 3) así como de la delimitación de las entidades susceptibles de ser consideradas beneficiarias del mecenazgo de las que son excluidas por la Ley 49/2002, en los términos expuestos, las asociaciones no declaradas de utilidad pública así como los empresarios pese a ser, en ambos casos, potenciales destinatarios del micromecenazgo cultural, problema especialmente grave en la medida de que, como señala Hernández (2017: 372), “al ser una modificación puramente fiscal su alcance va a ser limitado, es más, va a crear una mayor discriminación entre las entidades que tienen reconocido el carácter de entidad no lucrativa y las que no".

(iii) Por otra parte, las críticas al cumplimiento de las obligaciones de información (a las que hemos hecho referencia) resultan de total aplicación a pesar del carácter poco significativo de las cantidades individualmente donadas. Por ello, en palabras de Ruiz Garijo (2017: 485) "debería introducirse algún tipo de franquicia fiscal que eliminase las trabas que existen en la actualidad. Especialmente para las donaciones puras y para las aportaciones a cambio de recompensa. De este modo, la recomendación sería dejar exentas (vía exención, reducción de la base imponible o bonificaciones en cuota) las donaciones de pequeña cuantía, así como los productos o servicios que se entregan como contraprestación a dichas donaciones. Se liberaría, además, de los importantes deberes materiales y formales".

(iv) Por último, como analizaremos en el siguiente apartado, la LRF-ENL establece un régimen de deducciones en la cuota del IRPF y del IS (arts. 19 y 20). Este régimen de deducciones se intenta privilegiar por el legislador, incrementando los porcentajes de deducción, siempre que en los dos períodos impositivos inmediatos anteriores las donaciones se hubieran realizado en favor de una misma entidad por un importe igual o superior, en cada uno de ellos, al del ejercicio anterior. Esta técnica de incentivación puede contravenir la figura del crowdfunding cuando se configura como mecanismo de financiación de proyectos concretos que se agotan con su realización y que son promovidos, cada uno de ellos, por una multiplicidad de entidades vinculadas a cada proyecto y en las que sensibilización del donante recae más en el proyecto en sí mismo considerado que en la entidad que lo promueve. En cualquier caso, la citada técnica de fidelización de los donativos se presenta como una barrera para la diversificación (antítesis de la fidelización) de los posibles destinatarios del mecenazgo.

En definitiva, pese a la trascendencia de los problemas apuntados, las legislaciones autonómicas se limitan a definir la figura del crowdfunding pero sin mención ni ajuste normativo alguno que recoja la especificidad de esta fuente de financiación acorde a su condición de "verdadero espacio emergente de las 
posibilidades de la participación de la sociedad civil en la financiación de la cultura" (Rausell, Montagut y Minyana, 2013: 229). Así, la LMC-CV, y en similares términos las normas balear y castellano-manchega, define al micromecenazgo cultural, científico y deportivo no profesional, como "la financiación de un proyecto o actividad de esta índole que haya sido declarada o que ostente la consideración de interés social, mediante muchas aportaciones individuales realizadas con carácter altruista" (art. 2.2. LMC-CV), estableciéndose así un reconocimiento legislativo de esta figura, pero huérfano del correspondiente desarrollo normativo que la configure adecuadamente.

\section{Régimen fiscal de los donativos y donaciones}

\subsection{Efectos fiscales de los donativos, donaciones y aportaciones en sede del donante.}

\section{(i) Deducciones por donaciones y donativos en la LRF-ENL}

La Ley 49/2002 estableció, en su redacción inicial, una deducción en la cuota del impuesto personal sobre la renta del donante -del $25 \%$ en el IRPF y del $35 \%$ en el IS- por los donativos, donaciones o aportaciones realizadas en favor de las entidades beneficiarias del mecenazgo (arts. 19 y 20). Paralelamente, la LIRPF mantiene -desde su aprobación- una deducción del $10 \%$ de las cantidades donadas a las fundaciones legalmente reconocidas que rindan cuentas al órgano del protectorado correspondiente, así como a las asociaciones declaradas de utilidad pública no acogidas a la Ley 49/2002 (art. 68.3.b LIRPF).

Posteriormente, la Ley 27/2014, del Impuesto sobre Sociedades, con el objetivo de "estimular la fidelización de las donaciones realizadas tanto por personas físicas como por personas jurídicas" (Exposición de Motivos) dio nueva redacción a los citados arts. 19 y 20 de la LRF-ENL incrementando los porcentajes aplicables a la base de la deducción por donativos, donaciones y aportaciones. A tal fin, en el ámbito del IRPF se estableció un porcentaje del 75\% hasta los 150 primeros euros computables y del 30\% respecto del resto de la base de deducción (este último porcentaje se eleva al 35\% si en los dos períodos impositivos inmediatos anteriores dichas donaciones se hubieran realizado en favor de una misma entidad donaciones por un importe igual o superior, en cada uno de ellos, al del ejercicio anterior). Del mismo modo, en el ámbito de la imposición societaria se permite a los sujetos pasivos del IS deducir de la cuota íntegra del impuesto el 35\% de la base de la deducción (si en los dos períodos impositivos inmediatos anteriores se hubieran realizado donativos, donaciones o aportaciones con derecho a deducción en favor de una misma entidad por importe igual o superior, en cada uno de ellos, al del período impositivo anterior, el porcentaje de deducción aplicable a la base de la deducción en favor de esa misma entidad será el 40\%).

Por último, a raíz de la crisis derivada del COVID-19, se ha promulgado el anteriormente citado Real Decreto-ley 17/2020, por el que se aprueban medidas de apoyo al sector cultural y de carácter tributario para hacer frente al impacto económico y social del COVID-19 considerándose "imprescindible", dice la Exposición de Motivos de esta norma, "incrementar la participación ciudadana en la financiación de proyectos de mecenazgo". Mediante dicho RD-ley (DF $2^{\mathrm{a}}$ ) se modifica el art. 19.1 de la Ley 49/2002, elevando en cinco puntos porcentuales los porcentajes de deducción previstos para las donaciones efectuadas por contribuyentes del IRPF (y a los contribuyentes del IRNR que operen en territorio español sin establecimiento permanente). Sin embargo, el ajuste normativo no ha alterado el régimen de deducciones en la cuota del IS (art. 20 Ley 49/2002) ni, tanto en este impuesto como en el IRPF, los límites que, como seguidamente trataremos, afectan al plazo para poder practicar las deducciones que no hayan podido minorar las correspondientes cuotas íntegras en los términos establecidos en la LIS y en la LIRPF.

Partiendo de las normas citadas resulta evidente (como anteriormente apuntábamos) que el mecanismo utilizado por los arts. 19 y 20 Ley 49/2002 para "estimular la fidelización de las donaciones" no afianza el compromiso de los donantes para con una determinada entidad, sino que privilegia a las donaciones efectuadas en un concreto ejercicio a una determinada entidad y siempre que el importe de dicha donación se mantenga o incremente en el tiempo. Paralelamente, el procedimiento arbitrado por el legislador (aumentando los porcentajes de deducción respecto a los donativos fidelizados) puede conllevar, como efecto perverso, que el donante se retraiga de incrementar sus donativos en algún ejercicio en el que, pese a disfrutar de una renta disponible superior, no aumente sus donaciones (a esa concreta entidad destinataria de sus aportaciones) para no ver mermados sus porcentajes de deducción en posteriores periodos impositivos. Esta circunstancia se puede producir si el contribuyente estima que, en dichos ejercicios venideros, disminuirá su capacidad de aplicar su renta a estos fines. Además, con esta técnica legislativa se dificulta la diversificación de los beneficiarios de sus donativos dado que, para disfrutar de los porcentajes de deducción incrementados, se exige el mantenimiento de la aportación a una misma entidad expulsándose, dadas unas disponibilidades del mecenas, a terceras entidades potencialmente destinatarias de sus aportaciones.

Por lo que a la base de deducción se refiere la Ley 49/2002 distingue entre donativos dinerarios y donativos de bienes o derechos. En el primer caso la base de deducción será el importe donado. En el 
segundo, los bienes o derechos se valorarán atendiendo al valor contable que tuviesen en el momento de la transmisión y, en su defecto, el valor determinado conforme a las normas del Impuesto sobre el Patrimonio.

Entendemos que el sistema resulta inadecuado. En el supuesto de donaciones de bienes y derechos nos encontramos, en primer lugar, con una distinta valoración de la donación de un bien o derecho según se encuentre afecto o no a una actividad económica (valor contable / normas del IP). En segundo lugar, la valoración resultante normalmente diferirá del valor de mercado del bien o derecho donado. Así el valor contable vendrá dado por el coste de adquisición del bien o derecho donado minorado por las correspondientes amortizaciones. Por su parte la valoración a efectos del IP se establece, en determinados supuestos, en base a criterios objetivos referenciados bien a un periodo temporal (no a la fecha de la donación o aportación) bien al mayor valor de entre los que, a tal fin, indica la LIP [-valor catastral/comprobado/valor de adquisición (inmuebles); saldos medios (cuentas corrientes); valor de negociación media del cuarto trimestre (valores negociados); etc.-].

A nuestro juicio, el importe de la base de valoración sobre la que aplicar el correspondiente porcentaje de deducción debiera ser el valor de mercado del bien donado. Si un determinado elemento es enajenado y el importe de su realización es donado a una ENL acogida a la Ley 49/2002, la cuantía así obtenida será la valoración de su donación. Del mismo modo, si el bien fuere directamente donado a la ENL su valor de mercado debiera constituir igualmente la valoración de la deducción derivada de esta donación, sin que quepa discriminar las aportaciones no dinerarias respecto a las efectuadas en efectivo (lo que no obsta para que se establezcan proporcionados controles administrativos de las valoraciones efectuadas a fin de evitar interesadas sobrevaloraciones del bien o derecho donado), como tampoco cabe discriminar atendiendo a la condición de empresario o no (persona física o jurídica) del donante.

Una vez valorado el acto dispositivo, el importe que, efectivamente, constituirá la base de la deducción a practicar, se encuentra legalmente sujeto a determinados límites. Así, en el ámbito del IRPF, la Ley 35/2006 previene que la base de las deducciones por donativos y otras aportaciones no podrá exceder del 10\% de la base liquidable del contribuyente; sin que la cuantía de deducción no practicada, por insuficiencia de base, pueda trasladarse a ejercicios posteriores (arts. 68.3 y 69 LIRPF). Paralelamente, el resultado de minorar la cuota íntegra en las distintas deducciones (estatales o autonómicas, concernientes o no al mecenazgo), no podrá ser negativo (arts. 67.2 y 77.2 LIRPF).

Así pues, estas disfunciones del sistema merman doblemente la virtualidad de los incentivos fiscales al mecenazgo. En primer lugar, al limitar el importe de la base de las deducciones y, en segundo lugar, al imposibilitar la deducibilidad fiscal de las donaciones por insuficiencia de cuota íntegra. Por contra, en sede del IS las cantidades no deducidas por dicha insuficiencia de cuota podrán aplicarse en las liquidaciones de los períodos impositivos que concluyan en los diez años inmediatos y sucesivos. La base de esta deducción no podrá exceder del $10 \%$ de la base imponible del período impositivo pero se permite que las cantidades que excedan de dicho límite puedan aplicarse en los períodos impositivos que concluyan en los diez años inmediatos y sucesivos (art. 20 Ley 49/2002).

A pesar de las deficiencias ahora apuntadas, la reforma operada mediante el RD-ley 17/2020, antes reseñado, no ha modificado ni los límites que operan sobre la base de deducción ni el periodo para aplicar las deducciones no practicadas en el ejercicio. Así pues, con este ajuste normativo se aumentan los porcentajes (en sede del IRPF) de deducción pero se mantienen (tanto en el IRPF como en el IS) los límites en términos de porcentaje de unas bases que, en una coyuntura condicionada por la pandemia, necesariamente van a mermar, sin que se amplíe (en sede del IS) o se establezca (en el sede del IRPF) el plazo para la aplicación en ejercicios posteriores de las deducciones no practicadas por insuficiencia de bases o cuotas.

\section{(ii) Deducciones por donaciones y donativos en las leyes de mecenazgo autonómicas}

Veamos ahora las deducciones en la cuota íntegra autonómica del IRPF en sede del donante derivadas de las leyes de mecenazgo autonómicas. Como venimos recordando, las comunidades autónomas solamente tienen competencias, por lo que a la imposición sobre la renta se refiere, en la tributación de la renta de las personas físicas no sobre la imposición societaria. Estas competencias se traducen en la posibilidad de establecer deducciones que minorarán (junto a las deducciones a que se refiere el art. 77.1.a de la LIRPF) la cuota íntegra autonómica, sin que el resultado de estas operaciones pueda ser negativo.

Comenzando por las Islas Baleares el sistema por ella establecido resulta especialmente perfectible. En principio, en el ámbito de esta comunidad autónoma se establece una deducción del 15\% (del 25\% cuando el beneficiario del mecenazgo sea la Administración autonómica y el proyecto o la actividad cultural objeto del mecenazgo constituya un proyecto propio de la Administración autonómica) de las cuantías en que se valoren las donaciones, las cesiones de uso o los contratos de comodato y de las cuantías satisfechas en virtud de convenios de colaboración empresarial efectuados de acuerdo con lo que dispone la LMC-II.BB. (arts. 10 y 13). Sin embargo, el límite de la deducción aplicable es de 600 euros por ejercicio, estando condicionada la aplicación de esta deducción al hecho de que la base imponible total del contribuyente no supere la cuantía de 12.500 euros en el caso de tributación individual y de 25.000 euros en el caso de 
tributación conjunta ${ }^{10}$. Resulta palmario que estos límites de deducción, especialmente los concernientes a la limitación de la base imponible total del contribuyente, dejan prácticamente vacía de contenido esta deducción.

Mejor valoración merece la normativa valenciana, la cual previene una deducción del $25 \%$ en la cuota del IRPF por donaciones relativas al patrimonio cultural valenciano, por donaciones destinadas al fomento de la lengua valenciana, y por donaciones o préstamos de uso o comodato destinados a otros fines de interés cultural, científico o deportivo no profesional, siendo necesario en éstas últimas que los proyectos o actividades hayan sido declarados o tengan la consideración de interés social para poder beneficiarse de los mencionados incentivos fiscales. La base de las deducciones ${ }^{11}$ no podrá superar el $30 \%$ de la base liquidable del contribuyente. Se aumenta así el límite del 10\% establecido tanto en la Ley 49/2002 como en la legislación balear y la castellano-manchega (a la que seguidamente nos referiremos). Además, se previene una deducción ${ }^{12}$ por la adquisición de abonos culturales de empresas o instituciones adheridas al convenio específico suscrito con la entidad "Culturarts Generalitat Valenciana".

Paralelamente, la legislación de la comunidad castellano-manchega ${ }^{13}$ establece una deducción de la cuota íntegra autonómica del IRPF del 15\% por: (i) las donaciones de bienes que, formando parte del patrimonio cultural de Castilla-La Mancha, se realicen a favor de la Administración autonómica, universidades que desarrollen su actividad en el territorio de la Región, fundaciones y asociaciones declaradas de utilidad pública, siempre que persigan fines de naturaleza exclusivamente cultural y se hallen inscritas en los correspondientes registros; (ii) las cantidades destinadas a la conservación, reparación y restauración de bienes pertenecientes al patrimonio cultural de CLaM y (iii) las cantidades donadas para fines culturales establecidos en la LMC-CLaM, realizadas a las entidades que se establecen en el art. 3.1 de dicha ley, incluidos en el plan de mecenazgo cultural de Castilla-La Mancha. La suma de las bases de las deducciones así establecidas no podrá exceder del $10 \%$ de la base liquidable del contribuyente.

Más atractiva resulta la novedosa introducción por la ley castellano-manchega de la figura del crédito fiscal, definida como las "cantidades reconocidas por la Administración regional a favor de las personas contribuyentes que puedan ser utilizadas por los mismos para satisfacer el pago de los impuestos, precios públicos y tasas, gestionados directamente por la Junta de Comunidades de Castilla-La Mancha, así como del canon establecido en la Ley 9/2001, de 21 de marzo por la que se crea el canon Eólico". Este crédito fiscal tiene una vigencia de tres años y su importe será del $25 \%$ de los convenios de colaboración empresarial o de los importes dinerarios donados a la administración autonómica, Universidades siempre que se destinen a la financiación de programas de gasto o actuaciones que tengan por objeto la promoción actividades culturales, investigación en materia de servicios y productos de contenido cultural y el establecimiento de becas para el acceso a la educación superior en estudios relacionados con dichos servicios y productos (arts. 21 y 22 LMC-CLaM).

En último término, y a diferencia de lo indicado en relación a las magras medidas legislativas adoptadas en el ámbito de la Ley 49/2002 a través del RD-ley 17/2020 para paliar los efectos derivados de la crisis del COVID-19, las legislaciones autonómicas que analizamos no han modificado el régimen de deducciones a aplicar por donativos concernientes al mecenazgo cultural.

Una vez descritas las deducciones autonómicas procede detenernos en cómo las distintas normativas abordan la valoración de las aportaciones, es decir, la base de las deducciones reseñadas, uno de los apartados que como hemos anteriormente apuntado resulta censurable, distinguiendo de un lado la normativa valenciana y de otro la balear y castellano-manchega. Así, la norma valenciana reproduce los criterios de valoración establecidos en la Ley 49/2002, salvo en lo relativo a la constitución de un derecho real de usufructo sobre bienes inmuebles en el que mantiene el mismo criterio objetivo (un porcentaje a aplicar sobre el valor catastral) pero cuantificado en $4 \%$ de dicho valor catastral frente al $2 \%$ establecido en la LRFENL. Por su parte, las normativas de las Illes Balears y de Castilla-La Mancha se limitan a indicar, con idéntica redacción, que las reducciones de la base imponible y las deducciones de la cuota liquidable permitidas en las correspondientes leyes de mecenazgo se practicarán de acuerdo con la ley reguladora del tributo correspondiente (arts. 8 y 20.1 de, respectivamente, la LMC-II.BB. y la LMC-CLaM). Establecen así una genérica remisión normativa a la "ley reguladora del tributo correspondiente". No obstante, estas dos comunidades, y del mismo modo en ámbito de la Comunidad Valenciana, se refieren expresamente a la base de deducción del contrato de comodato (figura esta que, recordamos, a diferencia de la Ley 49/2002 sí que es

10 Artículo 5 bis Decreto Legislativo 1/2014, de 6 de junio, por el que se aprueba el Texto Refundido de las disposiciones legales de la Comunidad Autónoma de las Illes Balears en materia de tributos cedidos por el Estado.

11 Artículo 4.Dos Ley 13/1997, de 23 de diciembre, por la que se regula el tramo autonómico del IRPF y restantes tributos cedidos de la Comunidad Valenciana.

12 Artículo 4. Uno. Ley 13/1997: x) Deducción por cantidades destinadas a abonos culturales. "Los contribuyentes con rentas inferiores a 50.000 € podrán deducirse el $21 \%$ de las cantidades satisfechas por la adquisición de abonos culturales de empresas o instituciones adheridas al convenio específico suscrito con Culturarts Generalitat sobre el Abono Cultural Valenciano. A estos efectos, se entenderá por rentas del contribuyente que adquiera los abonos culturales, la suma de su base liquidable general y de su base liquidable del ahorro. La base máxima de la deducción a estos efectos será de $150 €$ por periodo impositivo".

13 Artículo 11 bis Ley 8/2013, de 21 de noviembre, de Medidas Tributarias de Castilla-La Mancha. 
considerada por las tres normativas autonómicas) cuantificando dicha base de deducción en el importe anual que resulte de aplicar, en cada uno de los periodos impositivos del contrato, el $4 \%$ a la valoración del bien efectuada por el organismos autonómico correspondiente. En caso de que se trate de locales se aplicará el $4 \%$ anual al valor catastral.

\section{(iii) Donativos, donaciones y aportaciones y base imponible del donante}

Como hemos apuntado, en el ámbito de aplicación de la LRF-ENL los donativos, donaciones y aportaciones efectuadas a las entidades beneficiarias del mecenazgo generarán el derecho a practicar determinas deducciones en la imposición personal del donante (persona física o jurídica). Paralelamente, están exentas del IRPF y del IS (o del IRNR) que grave la renta del donante o aportante las ganancias patrimoniales y las rentas positivas que se pongan de manifiesto con ocasión de dichos donativos (art. 23 Ley 49/2002).

Sin embargo, de este régimen fiscal privilegiado quedan expulsados (pues carecen de la consideración de entidades beneficiarias del mecenazgo a los efectos de la Ley 49/2002) actores tan importantes en el desarrollo del mecenazgo cultural como son las asociaciones no declaradas de utilidad pública así como los empresarios -personas físicas o jurídicas- que ejerzan actividades culturales. Con ello, las donaciones efectuadas por los sujetos pasivos del Impuesto sobre Sociedades a las denominadas por las legislaciones autonómicas empresas culturales titularidad de un empresario -persona física o jurídica- van a tener la consideración de liberalidad y, por lo tanto, no serán gasto fiscalmente deducible para la determinación de la base imponible del Impuesto sobre Sociedades del donante -sujeto pasivo del IS- al considerarse que dicho gasto no está correlacionado con los ingresos. Además, en el caso de que la donación sea en especie, puede generarse una ganancia patrimonial (calculada por diferencia entre el valor de mercado del elemento transmitido y su valor fiscal -art. 14.4 LIS-) plenamente sujeta al impuesto societario y que, en consecuencia, deberá integrar el donante en su base imponible. Por su parte, las cantidades aportadas (dinerarias o en especie) no generarán el derecho a practicar deducción por este concepto.

Del mismo modo, si el donante es persona física podrá tener un incremento de patrimonio (puesto de manifiesto con ocasión de los donativos, donaciones y aportaciones que efectúe) plenamente sujeto al IRPF si el destinatario no es una entidad acogida a la Ley 49/2002. Entre estas entidades se encuentran, reiteramos, las asociaciones no declaradas de utilidad pública o las empresas culturales. Igualmente, este acto dispositivo (al igual que los donativos dinerarios) no generará el derecho a practicar deducción alguna al amparo de la Ley 49/2002. No obstante, como se ha indicado, el art. 68.3 de la LIRPF establece una deducción del 10\% de las cantidades donadas a las fundaciones legalmente reconocidas que rindan cuentas al órgano del protectorado correspondiente, así como a las asociaciones declaradas de utilidad pública, no acogidas a la Ley 49/2002.

Sentado lo anterior, el reconocimiento en las normativas de las comunidades autónomas analizadas de las empresas culturales (así como de las asociaciones no declaradas de utilidad pública en el ámbito de la ley de mecenazgo castellano-manchega) como entidades beneficiarias del mecenazgo va a permitir la práctica de determinadas deducciones autonómicas por parte de donantes sujetos pasivos del IRPF, no así, como acabamos de ver, para los donantes sujetos pasivos del Impuesto sobre Sociedades, para los que el acto dispositivo tendrá el carácter de gasto no deducible. No obstante, las rentas y ganancias patrimoniales que afloren con motivo de esta donación se encontrarán, en todo caso, plenamente sujetas en la imposición personal del donante (persona física o jurídica) que deberá integrar en su base imponible.

\subsection{Régimen fiscal del donatario}

En el ámbito del Impuesto sobre Sociedades, el art. 6.1 ${ }^{\circ}$.a) de la Ley 49/2002 declara la exención en dicho impuesto de, entre otros, los donativos y donaciones recibidos para colaborar en sus fines por las ENL acogidas a la Ley 49/2002. Para el resto de entidades e instituciones sin ánimo de lucro no sujetas a la LRFENL resultará de aplicación el régimen de entidades parcialmente exentas prevenido en los arts. 109-111 de la LIS.

A este respecto, el art. 110.1.b) de la LIS declara exentas las rentas "derivadas de adquisiciones y de transmisiones a título lucrativo, siempre que unas y otras se obtengan o realicen en cumplimiento de su objeto o finalidad específica". Sin embargo, la norma excepciona esta exención al indicar que la misma "no alcanzará a los rendimientos de actividades económicas, ni a las rentas derivadas del patrimonio, ni a las rentas obtenidas en transmisiones, distintas de las señaladas en él" (art. 110.2 LIS). La literalidad del precepto puede llevar a entender que, tratándose de donaciones de bienes que se afectan a una actividad económica desarrollada por la ENL, la renta estará plenamente sujeta (no exenta) al Impuesto sobre Sociedades. Sin embargo, como señala Blázquez (2013: 478), "la donación de un bien destinado a una actividad empresarial en cumplimiento de fines no está contemplada entre las excepciones del artículo 121.3 (hoy 110.2 LIS), pues no parece que pueda ser calificada ni como rendimiento, ni renta derivada de su 
patrimonio ni renta derivada de transmisiones. Por tanto, creemos que estas donaciones deberían estar exentas".

Sentado lo anterior, tratándose de las empresas culturales, las donaciones percibidas se encontrarán plenamente sujetas en la imposición personal del beneficiario sea éste persona física o jurídica. Así, la empresa cultural con forma societaria receptora de la donación integrará en la base imponible de su Impuesto sobre Sociedades la aportación recibida, sin que las legislaciones autonómicas puedan establecer, por carecer de capacidad normativa, reducción, bonificación o deducción alguna. Del mismo modo, si la receptora de fondos es una empresa cultural cuya titularidad corresponde a una persona física, las aportaciones que reciba estarán sujetas al ISyD, correspondiendo a cada comunidad autónoma establecer el beneficio fiscal que considere. Sin embargo, las normativas autonómicas se limitan, con alguna matización, a incrementar las reducciones ya existentes con carácter general en las respectivas leyes de cesión de tributos para determinadas adquisiciones lucrativas inter vivos. Veamos sus especialidades.

La comunidad autónoma de las Illes Balears, establece una reducción del $70 \%$ en la valoración de las donaciones dinerarias efectuadas por determinados donantes (donaciones efectuadas de padres a hijos o a otros descendientes o entre colaterales hasta el tercer grado) y con un objetivo específico: "que se destinen a la creación de una empresa cultural ... tanto si es una empresa individual, como si es un negocio profesional o una entidad societaria, mediante la adquisición originaria de acciones o participaciones". Adviértase que el destino de las cantidades no es su afectación al desarrollo de tales actividades propias de las empresas culturales sino su constitución ${ }^{14}$.

En sede de la Comunidad Valenciana el art. 10 bis. $6^{\circ}$ la ley de cesión de tributos a esta comunidad, dispone que en las transmisiones inter vivos de importes dinerarios destinadas al desarrollo de una actividad empresarial o profesional, con fondos propios inferiores a 300.000 euros, en ámbito de la cinematografía, las artes escénicas, la música, la pintura y otras artes visuales o audiovisuales, la edición, la investigación o en el ámbito social, la base imponible del impuesto tendrá una reducción de hasta 1.000 euros. Ahora bien, como señala Casanellas (2016: 48) hubiera sido más adecuado considerar como magnitud de referencia, a efectos del establecimiento de un límite para su aplicación, el importe neto de la cifra de negocios pues la consideración de los fondos propios "únicamente tiene sentido en relación con las personas jurídicas ... Además su importe puede ser de fácil modificación por parte de los socios y, por tanto, puede ser ajustado, a conveniencia, al importe que corresponda para poder entrar dentro del límite fijado por la ley".

En último término, la normativa castellano-manchega previene una reducción (variable en función del periodo de cesión) en la base imponible del Impuesto sobre Sucesiones y Donaciones para aquellos bienes incluidos en el Catálogo del Patrimonio Cultural de Castilla-La Mancha, siempre que sean cedidos gratuitamente para el uso de carácter cultural propio de la entidad cesionaria y efectuada a favor de la Administración Pública de Castilla-La Mancha; de las Universidades con implantación en Castilla-La Mancha; de los Centros de Investigación y Centros Superiores de Enseñanzas Artísticas de la Región; y de las fundaciones y las asociaciones declaradas de utilidad pública, siempre que persigan fines de naturaleza exclusivamente cultural y se hallen inscritas en el registro correspondiente ${ }^{15}$.

\section{Conclusiones}

Como se ha contrastado, la Ley 49/2002 se encuentra superada por la realidad de un Tercer Sector que requiere de adecuados instrumentos de estímulo a la participación privada en las actividades de interés general, evidenciándose la necesidad de redefinir normativamente a las entidades susceptibles de ser consideradas beneficiarias del mecenazgo, los actos dispositivos generadores de beneficios fiscales para donantes y los mecanismos de incentivación fiscal al mecenazgo cultural.

Paralelamente, pese a que las comunidades autónomas de régimen general tienen, en su ámbito competencial, capacidad normativa para regular el régimen fiscal del mecenazgo, únicamente las comunidades de las Illes Balears, Valencia y Castilla-La Mancha han promulgado las correspondientes leyes del mecenazgo cultural. Sin embargo, este desarrollo normativo autonómico adolece del calado suficiente para considerar salvados, en sus respectivos ámbitos de aplicación, los reparos que hemos formulado a la vigente Ley 49/2002. Dichas salvedades conciernen tanto al alcance de las modificaciones normativas introducidas por las leyes de mecenazgo autonómicas como a la reproducción que efectúan, en determinados supuestos, de las deficiencias advertidas en la LRF-ENL. Del mismo modo, dado que las comunidades autónomas de régimen general carecen de competencias en el ámbito de la imposición societaria, se ven

14 Para su disfrute se exige el cumplimiento de, entre otros, los siguientes requisitos: (i) la base de la reducción es el importe efectivamente invertido en la creación de la empresa, con un máximo de 300.000 euros (ii) la cifra anual de negocio de la empresa no puede superar el límite de 2.000.000 euros durante los cuatro años desde su creación (iii) el donatario debe tener un patrimonio preexistente inferior a 400.000 euros en el momento de la formalización de la donación (art. 45 bis Ley Cesión Tributos Illes Balears).

15 Artículo 16 bis Ley 8/2013, de 21 de noviembre de Medidas Tributarias de Castilla-La Mancha. 
privadas de mecanismos para reorientar los comportamientos de los sujetos pasivos de este impuesto restringiéndose, en consecuencia, los potenciales agentes que pueden gozar en su imposición sobre la renta de los incentivos fiscales al mecenazgo establecidos por las comunidades autónomas.

A esta dispersión legislativa procede añadir la falta de coordinación entre las legislaciones estatal y autonómica que confluyen en el ámbito objeto de nuestro estudio. Así, ante un mismo presupuesto de hecho pueden generarse discrepancias entre ambas jurisdicciones fiscales al abordar la posible condición de entidad beneficiaria del mecenazgo o al cuantificar la valoración del acto que genera el derecho a practicar determinadas deducciones. Adviértase que el reparo ahora señalado no aboga por una uniformidad normativa sino por su necesaria coordinación. Recapitulemos algunas de estas consideraciones.

1. Tanto la Ley 49/2002 como las normativas balear y valenciana mantienen, en sus ámbitos de aplicación, la perniciosa exigencia de la declaración de utilidad pública de las asociaciones para ser consideradas entidades beneficiarias del mecenazgo. Su no calificación como tales les priva del atractivo derivado de la deducibilidad fiscal de las donaciones efectuadas a estas entidades. No obstante, la legislación castellano-manchega integra -con la matización apuntada- a las asociaciones no declaradas de utilidad pública junto al resto de personas y entidades beneficiarias del mecenazgo cultural de esta comunidad autónoma.

2. Las tres leyes autonómicas analizadas recogen a las denominadas empresas culturales como entidades beneficiarias del mecenazgo. Ahora bien, al no disponer las comunidades autónomas de régimen general de capacidad normativa en el ámbito del IS, las donaciones efectuadas por los sujetos pasivos de este impuesto a dichas empresas culturales carecerán de incentivo fiscal alguno en su correspondiente impuesto societario. Paralelamente, se desvincula la deducibilidad fiscal de la aportación efectuada en sede del donante y el régimen fiscal de la entidad beneficiaria. A nuestro juicio, las donaciones obtenidas por las personas o entidades beneficiarias del mecenazgo debieran resultar exentas en su imposición sobre la renta.

3. En aquellos supuestos en los que la destinataria del mecenazgo sea una entidad residente en otros estados miembros de la UE resultarán de aplicación en sede del donante, atendiendo a la doctrina del TJCE, los incentivos fiscales al mecenazgo. Así lo recoge -únicamente- la ley de mecenazgo valenciana. No obstante, quedan sin resolver (amén de su expresa inclusión en las respectivas normativas) los problemas derivados de la merma de recaudación resultante del incentivo fiscal en la jurisdicción fiscal del donante y que redundan en beneficio otro ámbito territorial así como el establecimiento de un sistema de intercambio de información armonizado.

4. La Ley 49/2002 así como las leyes de mecenazgo autonómicas establecen que la efectividad de los donativos, donaciones y aportaciones deducibles debe justificarse mediante certificación expedida por la entidad beneficiaria, la cual deberá remitir a la Administración tributaria determinada información sobre las certificaciones expedidas. No obstante, la LMC-CLaM prevé el desarrollo de una aplicación informática que posibilite la realización de forma electrónica de estas donaciones. Este mecanismo junto al posible establecimiento de una franquicia que exonere de la obligación de comunicar las cantidades percibidas, minorarían la carga fiscal indirecta que recae sobre las personas y entidades beneficiarias del mecenazgo.

5. Respecto a la delimitación de los actos dispositivos de donantes y mecenas susceptibles de ser incentivados fiscalmente tanto la Ley 49/2002 como las leyes de mecenazgo autonómicas analizadas limitan el derecho a practicar determinadas deducciones derivadas de "donativos, donaciones y aportaciones irrevocables, puros y simples". Sin embargo, junto al enriquecimiento del donatario, en este acto de liberalidad puede concurrir una proporcionada contraprestación, carente de significatividad, en favor del donante o una carga impuesta a la entidad beneficiaria siempre que con ello no se desnaturalicen los fines de la entidad beneficiaria. Paralelamente debiera reconsiderarse el tratamiento a dispensar a las donaciones con causa mixta.

6. Del mismo modo, el mero reconocimiento del donante por parte de la entidad beneficiaria no debiera ser óbice para desvirtuar su carácter de "irrevocable, puro y simple" de las donaciones, máxime en el ámbito empresarial, en la medida de que las políticas de responsabilidad social corporativa conllevan una necesaria visibilización de su actuar filantrópico que produce un retorno indirecto de sus acciones de mecenazgo en términos de reputación corporativa y define en sus justos términos el carácter "puro y simple" de las donaciones. Frente a la rigidez de la normativa estatal, las comunidades autónomas de Valencia y Castilla-La Mancha enfocan más adecuadamente el problema al promover la publicidad institucional de proyectos y actuaciones declaradas o consideradas de interés social para la captación de posibles mecenas así como la promoción del reconocimiento social de los donantes.

7. Igualmente, determinados negocios jurídicos a título gratuito, como el contrato de comodato, no son recogidos de forma expresa en la norma estatal si bien la DGT asimila estas operaciones a la donación de derechos que, como tal, se valorará bien por su valor contable bien por su valor de mercado. Por el contrario, las normativas autonómicas sí que recogen expresamente esta figura como 
mecanismo específico de incentivo fiscal al mecenazgo cultural aunque limitándolo a determinados elementos y estableciendo un criterio de valoración objetivo al margen de cualquier referencia al valor de mercado. Se patentiza la necesaria regulación coordinada del contrato de comodato y su adecuada cuantificación.

8. Resulta insuficiente la exclusiva referencia a la donación como acto dispositivo generador del derecho a practicar determinadas deducciones. Así, la aplicación de los incentivos fiscales al mecenazgo debiera tomar como referencia, en la Ley 49/2002 así como en las leyes de mecenazgo analizadas, la concurrencia del hecho imponible de la Ley del ISD (art. 3.1 Ley 29/1987: la adquisición de bienes y derechos por donación o cualquier otro negocio jurídico a título gratuito inter vivos) pues dicha redacción «daría cobertura a otros negocios que pueden suscitar alguna duda con la actual normativa» (Martín Dégano, 2017b: 129).

9. Tanto la Ley 49/2002 como las leyes autonómicas (excepción hecha de la balear) omiten las prestaciones gratuitas de servicios a las ENL entre los actos que generan el derecho a la práctica de deducción. Antes al contrario, en el supuesto de prestaciones gratuitas de servicios efectuadas por empresarios personas físicas resultarán obligados a integrar en sus respectivas bases imponibles unos beneficios irrealmente estimados. Del mismo modo el resarcimiento de los gastos en que incurre el personal voluntario es calificado como rendimiento del trabajo. En el ámbito de la imposición societaria, la prestación de servicios gratuitos a las entidades no lucrativas poniendo a disposición de estas entidades sus medios materiales y humanos es considerada una liberalidad, lo cual impedirá la deducibilidad fiscal en sede del Impuesto sobre Sociedades de los gastos asociados a los servicios así prestados sin que genere el derecho a practicar deducción alguna. El tratamiento fiscal de todos estos actos debe ser redefinido por el legislador reconociéndose en sus justos términos el derecho al resarcimiento de gastos en que incurra el voluntariado así como a la práctica de la deducción por las prestaciones servicios gratuitos efectuados por empresarios o profesionales y admitiéndose también la posible existencia de una compensación simbólica o reputacional para la persona o entidad que las realice, siempre que no tenga como finalidad principal la publicidad o propaganda de la misma.

10. La Ley 49/2002 no ha sido objeto de adecuación alguna que contemple el micromecenazgo como nueva forma financiación. Al tiempo, las legislaciones autonómicas se limitan a definir la figura del crowdfunding pero sin mención ni ajuste normativo alguno acorde con esta nueva realidad, reproduciéndose en definitiva las insuficiencias del sistema general del mecenazgo. La regulación del micromecenazgo debiera facilitar el acceso a esta fuente de financiación, y en particular, a las empresas culturales y a las asociaciones no declaradas de utilidad pública lo que, a la par, redundará en la transparencia de determinadas donaciones que hasta hora presentan contornos grises.

11. El estímulo de las donaciones a través de la denominada fidelización no cumple su objetivo de constituir un eficiente mecanismo de estímulo fiscal al mecenazgo. Su configuración, los efectos en la planificación fiscal del donante, los obstáculos para la diversificación de los destinatarios de las donaciones, lo convierten en una figura que privilegia las donaciones efectuadas en un concreto ejercicio a una determinada entidad y siempre que el importe de dicha donación se mantenga o incremente en el tiempo. A nuestro juicio, el estímulo fiscal a las donaciones se debiera vincular a incrementos en los porcentajes de deducción y a la potenciación institucional de la visibilización de la actuación del mecenas por la sociedad.

12. El importe de la base de la valoración sobre la que aplicar el correspondiente porcentaje de deducción debiera ser el valor de mercado del bien donado, rechazándose discriminaciones derivadas del carácter dinerario o en especie de la donación (lo que no obsta para que se establezcan proporcionados controles administrativos de las valoraciones efectuadas a fin de evitar interesadas sobrevaloraciones del bien o derecho donado), de la condición del donante (empresario o no) así como de la jurisdicción fiscal.

13. Del mismo modo, una política integral de estímulo al mecenazgo cultural debiera abordar, entre otros extremos, los porcentajes de deducción, los límites que afectan a las bases de deducción así como los plazos para aplicar las deducciones no practicadas (por insuficiencia de base o de cuota) tanto en sede del IS como del IRPF. Igualmente, es menester recalificar la deducibilidad en el ámbito del impuesto societario de las deducciones concernientes al mecenazgo establecidas en el ámbito autonómico, las ganancias patrimoniales que pudieran aflorar con ocasión de los donativos, donaciones y aportaciones que efectúe si el destinatario no es una entidad acogida a la Ley 49/2002 así como la generalización y extensión de los efectos de la figura del crédito fiscal introducida por la normativa castellano-manchega. 


\section{Referencias bibliográfícas}

Blázquez Lidoy, A. y Martín Dégano, I. (2012a) Manual tributario de entidades no lucrativas (asociaciones y fundaciones). $1^{\mathrm{a}}$. Madrid: Centro de Estudios Financieros.

Blázquez Lidoy, A. y Martín Dégano, I. (2012b) Aspectos problemáticos y propuestas de reforma de la Ley 49/2002 en materia de mecenazgo. Crónica Tributaria, $\mathrm{N}^{\circ} 145$, pp. 7-38.

Blázquez Lidoy, A. (2013) El impuesto sobre sociedades en las entidades sin fines lucrativos. En: Dir. Rúa Alonso de Corrales, E. La contabilidad de fundaciones y asociaciones. Aplicación práctica del Plan contable de las entidades sin fines lucrativos 2013. Madrid: Ediciones Cinca, pp. 468-513.

Blázquez Lidoy, A. (2015) La no-revisión del mecenazgo: historia de una reforma inconclusa. IUS CANONICUM, ${ }^{\circ}$ 55, pp. 197-229.

Blázquez Lidoy, A. (2017) La responsabilidad social corporativa y la necesaria revisión del gasto no deducible en la Ley del Impuesto sobre Sociedades (Ley 27/2014) (Análisis tomando en consideración el Derecho de los Estados Unidos de América). En: Dir. Cabra de Luna, M.A. La dimensión social de la fiscalidad: discapacidad, tercer sector y mecenazgo. Estudios en homenaje a Miguel Cruz Amorós. Madrid: Ediciones Cinca, pp. $240-277$.

Calvo Ortega, R. (2005) Fiscalidad de las entidades de economía social: cooperativas, mutuas, sociedades laborales, fundaciones, asociaciones de utilidad pública, centros especiales de empleo, empresas de inserción social. $1^{\mathrm{a}}$. Madrid: Civitas. 723 p.

Carbajo Vasco, D. (2017) Un apunte sobre la fiscalidad del voluntario. En: Dir. Cabra de Luna, M.A. La dimensión social de la fiscalidad: discapacidad, tercer sector y mecenazgo. Estudios en homenaje a Miguel Cruz Amorós. Madrid: Ediciones Cinca, 433-446.

Casanellas Chuecos, M. (2016) Nuevos marcos de apoyo fiscal al mecenazgo en España: perspectiva jurídica estatal y autonómica. Revista catalana de dret públic, $\mathrm{N}^{\circ}$ 52, pp. 43-66. DOI: 10.2436/20.8030.01.65.

García Luis, T. (2017) Micromecenazgo, fidelización de donaciones y otras reformas del régimen fiscal de incentivos al mecenazgo tras la Ley 27/2014, de 27 de noviembre, del Impuesto sobre Sociedades. En: Merino Jara, I. Entidades con valor social: Nuevas perspectivas tributarias. Madrid: Instituto Estudios Fiscales, pp. 509-549.

Hernández Lavado, A. (2017). El crowdfunding o micromecenazgo como instrumento de puesta en valor de la cultura y el patrimonio cultural y su fiscalidad. En: Merino Jara, I. Entidades con valor social: Nuevas perspectivas tributarias. Madrid: Instituto Estudios Fiscales, pp. 359- 376.

Jiménez Díaz, A. (1998) La exención de las fundaciones y la crisis fiscal del Estado. 1ª, Madrid: McGraw-Hill. p. 198.

Jiménez Escobar, J. (2017) Presupuestos, principios y medidas para la articulación de una reforma del régimen tributario del mecenazgo. Crónica Tributaria, $\mathrm{N}^{\mathrm{o}} 163$, pp. 95-122.

López Ribas, S. (2014) Incentivos fiscales sin fronteras para fundaciones y donantes europeos. Crónica Tributaria, $\mathrm{N}^{\mathrm{o}} 153$, pp. 221-259.

Martín Dégano, I. (2017a) El mecenazgo por medio del comodato: ¿donación o regulación específica? En: Merino Jara, I. Entidades con valor social: Nuevas perspectivas tributarias. Madrid: Instituto Estudios Fiscales, pp. 633-650.

Martín Dégano, I. (2017b) El concepto de donación a efectos de la aplicación de los incentivos fiscales al mecenazgo. En: Cruz Amorós, M. Fiscalidad del Mecenazgo. Madrid: Fundación Impuestos y Competitividad, pp. 123-147.

Martínez Bárbara, G. (2019) The Neverending Story: la reforma inacabada de la fiscalidad de las entidades sin fines lucrativos y de los incentivos fiscales al mecenazgo. Revista de Contabilidad y Tributación. CEF, No 441, pp. 5-40.

Montesinos Oltra, S. y Palacios Ronda, E. (2020) Fiscalidad de la economía social. En Chaves Ávila, R.; Fajardo García, I.G.; Monzón Campos, J.L. Manual de Economía Social. Valencia: Tirant lo Blanch, pp. 131-154.

Moreno González, S. (2017) Efectos fiscales del crowdfunding social: aspectos problemáticos y propuestas de lege ferenda. En: Merino Jara, I. Entidades con valor social: Nuevas perspectivas tributarias. Madrid: Instituto Estudios Fiscales, pp. 315-340.

Palacios Ronda, E. (2018) Financiación de asociaciones: examen especial del ejercicio de actividades económicas. Revista Vasca de Economía Social. Instituto de Derecho Cooperativo y Economía Social GEZKI de la Universidad del País Vasco, № 15, pp. 155-179.

Palacios Ronda, E. (2019) Utilidad pública de las asociaciones. Revocación por la Administración y solución fundacional. REVESCO. Revista de Estudios Cooperativos, Primer Cuatrimestre, No 130, pp. 99-121. DOI: 10.5209/REVE.60987.

Pedreira Menéndez, J. (2003) El régimen fiscal del sector no lucrativo y del mecenazgo. Comentarios a la Ley 49/2002, de 23 de diciembre, de régimen fiscal de las entidades sin fines lucrativos y de los incentivos fiscales al mecenazgo. $1^{\mathrm{a}}$. Madrid: Civitas. $456 \mathrm{p}$.

Pedreira Menéndez, J. (2017) Propuestas para la reforma del sector no lucrativo: especial consideración del aplicable a las fundaciones y al mecenazgo. En: Merino Jara, I. Entidades con valor social: Nuevas perspectivas tributarias. Madrid: Instituto Estudios Fiscales, pp. 493-508.

Rausell Köster, P.; Montagut Marqués, J. y Minyana Beltrán, T. (2013) Hacia nuevos modelos de financiación cultural ¿Renovar el mecenazgo? Periférica: Revista para el análisis de la cultura y el territorio, No14, pp. $209-232$.

Rodríguez de las Heras Balell, T. (2013) El crowdfunding: una forma de financiación colectiva, colaborativa y participativa de proyectos. Pensar en Derecho, N³, pp. 101-123. 
Ruiz Garijo, M. (2017) Reflexiones de urgencia sobre el impacto de la fiscalidad en la economía colaborativa. En: Merino Jara, I. Entidades con valor social: Nuevas perspectivas tributarias. Madrid: Instituto Estudios Fiscales, pp. 471-489.

Sanz Gómez, R.J. y Lucas Durán, M. (2015) Implicaciones tributarias del crowdfunding o financiación colectiva. Quincena Fiscal, Nº, pp. 19-69.

Suberbiola Garbizu, I. (2017) Consecuencias tributarias para los aportantes en plataformas de financiación colectiva o crowdfunding. En: Merino Jara, I. Entidades con valor social: Nuevas perspectivas tributarias. Madrid: Instituto Estudios Fiscales, pp. 377-389. 